\title{
Impact of Terrestrial Input on Deep-Sea Benthic Archaeal Community Structure in South China Sea Sediments
}

\author{
Dengxun Lai1,2, Brian P. Hedlund ${ }^{2,3}$, Wei Xie ${ }^{4,5}$, Jingjing Liu' ${ }^{1}$, Tommy J. Phelps ${ }^{6}$, \\ Chuanlun Zhang ${ }^{7,8,9,10 *}$ and Peng Wang ${ }^{1 *}$
}

${ }^{1}$ State Key Laboratory of Marine Geology, Tongji University, Shanghai, China, ${ }^{2}$ School of Life Sciences, University of Nevada, Las Vegas, NV, United States, ${ }^{3}$ Nevada Institute of Personalized Medicine, University of Nevada, Las Vegas, NV, United States, ${ }^{4}$ School of Marine Sciences, Sun Yat-sen University, Zhuhai, China, ${ }^{5}$ Southern Marine Science and Engineering Guangdong Laboratory (Zhuhai), Zhuhai, China, ${ }^{6}$ Earth and Planetary Sciences, University of Tennessee, Knoxville, Knoxville, TN, United States, ${ }^{7}$ Shenzhen Key Laboratory of Marine Archaea Geo-Omics, Southern University of Science and Technology, Shenzhen, China, ${ }^{8}$ Department of Ocean Science and Engineering, Southern University of Science and Technology, Shenzhen, China, ${ }^{9}$ Southern Marine Science and Engineering Guangdong Laboratory (Guangzhou), Guangzhou, China, ${ }^{10}$ Shanghai Sheshan National Geophysical Observatory, Shanghai, China

\section{OPEN ACCESS}

Edited by:

Michael W. Friedrich,

University of Bremen, Germany

Reviewed by:

Takuro Nunoura,

Japan Agency for Marine-Earth Science and Technology (JAMSTEC),

Japan

Gordon Webster, Cardiff University, United Kingdom

*Correspondence:

Chuanlun Zhang zhangcl@sustc.edu.cn; zhangcl@sustech.edu.cn Peng Wang pengwang@tongji.edu.cn

Specialty section: This article was submitted to

Biology of Archaea,

a section of the journal

Frontiers in Microbiology

Received: 12 June 2020 Accepted: 15 October 2020 Published: 05 November 2020

Citation:

Lai D, Hedlund BP, Xie W, Liu J, Phelps TJ, Zhang $C$ and Wang $P$ (2020) Impact of Terrestrial Input on

Deep-Sea Benthic Archaeal Community Structure in South China Sea Sediments.

Front. Microbiol. 11:572017. doi: 10.3389/fmicb.2020.572017
Archaea are widespread in marine sediments and play important roles in the cycling of sedimentary organic carbon. However, factors controlling the distribution of archaea in marine sediments are not well understood. Here we investigated benthic archaeal communities over glacial-interglacial cycles in the northern South China Sea and evaluated their responses to sediment organic matter sources and inter-species interactions. Archaea in sediments deposited during the interglacial period Marine Isotope Stage (MIS) 1 (Holocene) were significantly different from those in sediments deposited in MIS 2 and MIS 3 of the Last Glacial Period when terrestrial input to the South China Sea was enhanced based on analysis of the long-chain n-alkane $\mathrm{C}_{31}$. The absolute archaeal 16S rRNA gene abundance in subsurface sediments was highest in MIS 2, coincident with high sedimentation rates and high concentrations of total organic carbon. Soil Crenarchaeotic Group (SCG; Nitrososphaerales) species, the most abundant ammonia-oxidizing archaea in soils, increased dramatically during MIS 2, likely reflecting transport of terrestrial archaea during glacial periods with high sedimentation rates. Co-occurrence network analyses indicated significant association of SCG archaea with benthic deep-sea microbes such as Bathyarchaeota and Thermoprofundales in MIS 2 and MIS 3, suggesting potential interactions among these archaeal groups. Meanwhile, Thermoprofundales abundance was positively correlated with total organic carbon (TOC), along with n-alkane $\mathrm{C}_{31}$ and sedimentation rate, indicating that Thermoprofundales may be particularly important in processing of organic carbon in deep-sea sediments. Collectively, these results demonstrate that the composition of heterotrophic benthic archaea in the South China Sea may be influenced by terrestrial organic input in tune with glacial-interglacial cycles, suggesting a plausible link between global climate change and microbial population dynamics in deep-sea marine sediments.

Keywords: benthic archaea, thermoprofundales, thaumarchaeota, terrestrial input of organic matter, glacialinterglacial cycles 


\section{INTRODUCTION}

Long-term carbon sequestration in the form of organic matter (OM) deposited in marine sediments plays an important role in climate regulation. Currently, an estimated $7.8 \times 10^{22}$ grams of carbon are stored in marine sediments, including both terrestrial and marine sources (Mackenzie et al., 2004). The contributions of these distinct organic pools to marine sediment vary with climate, geologic time, and geographic location (Stein, 1990; Schubert and Calvert, 2001; Yamamoto and Polyak, 2009). Marine OM from organisms in the water column contains predominantly proteins and carbohydrates, whereas terrestrial components such as lignocellulose derived from vascular plants are generally more nitrogen-depleted (Hedges et al., 1997). It has been observed that marine OM is broadly more reactive than terrestrial OM (Prahl et al., 1997; Aller and Blair, 2004; Zhang et al., 2018; He et al., 2020) and thus remineralization of terrestrial OM is much less efficient than marine OM.

The differences in quantity and quality of organic matter likely have important influences on deep-sea microbial assemblages, which are generally considered food (organic carbon) limited (Smith et al., 2008). Bathyal sediments below $2000 \mathrm{~m}$ water depth comprise the majority of the sea floor (Dunne et al., 2007) and are generally oligotrophic, with low organic carbon content and low sedimentation rates (Seiter et al., 2004; Dunne et al., 2007). Due to low respiration rates, dissolved electron acceptors such as oxygen, nitrate, and sulfate can penetrate deep into oligotrophic sediments on the scale of meters (D'Hondt et al., 2004; D'Hondt et al., 2015). In contrast, coastal sediments are commonly rich in organic matter, which can consume those electron acceptors within millimeters to centimeters of the sediment depth.

Archaea, as an important component in the sedimentary biosphere, constitute a significant portion of the global biomass (Whitman et al., 1998; Danovaro et al., 2015; Hoshino and Inagaki, 2019) and are key drivers of organic matter remineralization in sediments (Biddle et al., 2006; Lloyd et al., 2013; Zhou et al., 2018). Genomic and transcriptomic data have shown that marine archaea can use diverse organic compounds including fatty acids, carbohydrates, and lipids as sources of carbon (Inagaki et al., 2006; Li et al., 2015). Archaea have been reported to be of similar abundance with bacteria and can even dominate in some marine sediments (Biddle et al., 2006; Lipp et al., 2008; Vuillemin et al., 2019). Some archaeal lineages are considered to constitute the in situ populations in typical subsurface sediments (Inagaki et al., 2006; Parkes et al., 2014). For example, Lokiarchaeota [previously referred to as Marine Benthic Group B (MBGB) or Deep-sea Archaeal Group (DSAG)] has been prominently observed in methane hydrate-bearing sediments (Inagaki et al., 2006; Nunoura et al., 2008; Dang et al., 2010). Bathyarchaeota [previously named Miscellaneous Crenarchaeotic Group (MCG)] is widespread in marine sediments, particularly the organic-rich sediments on continental margins (Kubo et al., 2012; Wang et al., 2020a). In addition, Thermoprofundales [formerly named Marine Benthic Group D (MBGD)], Hadesarchaeota [formerly named South African Gold Mine Euryarchaeotal Group (SAGMEG)], and Halobacteriales (Halobacteriaceae, Deep Sea Euryarchaeotic
Group, and Marine Hydrothermal Vent Group) have also been found in various oceanic regions (Sørensen and Teske, 2006; Heijs et al., 2008; Wang et al., 2014; Wang et al., 2020b).

Ammonia-oxidizing archaea (AOA) of the phylum Thaumarchaeota are ecologically widespread, occurring in terrestrial and marine habitats worldwide, and significantly contribute to global nitrogen cycle (Alves et al., 2018). AOA are regarded as important players in fueling microbial communities and sustaining oxic deep-sea benthic ecosystems (Orsi, 2018). Marine group I (MG-I; also named Nitrosopumilales or Group I.1a), the major AOA group in marine environments, constitutes the most abundant archaeal group in the global oceans (Könneke et al., 2005; Qin et al., 2014, 2020). MG-I in marine sediments were found to be diverse and phylogenetically distinct from those in water columns (Francis et al., 2005; Durbin and Teske, 2010; Wang et al., 2010). In contrast, Soil Crenarchaeotic Group (SCG; also named Nitrososphaerales or Group I.1b) has been found in various terrestrial environments such as soils (Tourna et al., 2011; Bouskill et al., 2012; Hong and Cho, 2015; Schneider et al., 2015), freshwater aquatic systems (Liu et al., 2014; Fillol et al., 2015), and hot springs (Zhang et al., 2008). Recent research has reported the identification of SCG over a wide spectrum of marine sediments (Li et al., 2008; Park et al., 2008; Dai et al., 2016; Alves et al., 2018) and even in a hadal trench (Nunoura et al., 2013); thus, the occurrence and ecological significance of this lineage is not fully understood.

While it is recognized that archaea are ubiquitous and play a crucial role in elemental cycling (D'Hondt et al., 2002; Offre et al., 2013), our understanding of the functions of marine benthic archaea, and the influence of climatic forces on the composition and function of marine benthic communities is far from complete. The influence of glacial runoff on bacterial communities in fjord sediments has been suggested (Pelikan et al., 2019). Consistent with this observation, terrestrially derived sediments have been shown to retain indigenous bacterial communities in marine deep-sea sediments for tens of millions of years (Inagaki et al., 2015). Additionally, analysis of 16S rRNA gene clone libraries from subsurface continental slope sediments has revealed that differences in bacterial and archaeal community composition could be associated with depositional environments (Nunoura et al., 2009). However, studies are lacking that integrate biological analyses with terrestrial input biomarkers and the geological time frames or climatic processes.

The South China Sea is one of the largest margin seas. Organic matter on the continental slope has complex compositions, which are affected by climate oscillations, especially glacial and interglacial cycles (Zhao et al., 2017). The large expansion of exposed continental shelf as the sea level decreased during the Last Glacial Period, especially the Last Glacial Maximum (LGM), led to an expansion of vegetation around the northern South China Sea (Zhou et al., 2012). During that time, a large amount of terrigenous material, including terrestrially derived organic carbon (TerrOC), was transported to the deep ocean via river and submarine canyons (Lin et al., 2016).

In this study, archaeal 16S rRNA gene characterization was performed in sediment from the Pearl River Submarine Canyon in the South China Sea to identify and quantify archaeal species 
in the context of geochemical and paleoecological signatures, with a goal to understand the potential impact of terrestrial input on deep-sea benthic archaeal community structure in South China Sea sediments.

\section{MATERIALS AND METHODS}

\section{Geological Setting and Sample Collection}

A sediment core from the Pearl River Submarine Canyon (MD12-3433Cq; $19^{\circ} 16.88^{\prime} \mathrm{N}, 116^{\circ} 14.52^{\prime} \mathrm{E}$; Water depth: $2125 \mathrm{~m}$ ) in the South China Sea was obtained (Figure 1) using a gravity corer during the Chinese-French joint MD190-CIRCEA cruise (June 12 to June 30, 2012). This site is located about $380 \mathrm{~km}$ southeast of Hong Kong. The core consisted of highly stratified sediments with colors from light (0 to $100 \mathrm{cmbsf})$ to deep gray (100 to $820 \mathrm{cmbsf}$ ). The sediments were characterized by continuous homogenous clay or silt without observable bioturbations, suggesting a stable depositional environment.

On board the research vessel, samples for microbial (archaeal and bacterial) analyses were carefully taken from the center of the core using sterilized tools. Thirty-six subsamples were collected into airtight sterile PVC tubes and stored in a $-80^{\circ} \mathrm{C}$ freezer until further analysis. Samples from the sediment core were assigned to one of the three Marine Isotope Stages (MISs) (Figure 2). Sediments in the top $1 \mathrm{~m}$ belonged to MIS 1 , those of the $1-3.5 \mathrm{~m}$ depth MIS 2, and those below $3.5 \mathrm{~m}$ depth MIS 3. MIS 1 and MIS 3 represent interglacial periods while MIS 2 represents a glacial period. MIS 3 is interstadial during the Last Glacial Period, which spans from MIS 2 to MIS 4.

\section{Determination of Environmental Parameters}

Total organic carbon (TOC) and total nitrogen were measured by Vario Cube CN (Germany Elementar Company). Briefly, sediment samples (around $0.5 \mathrm{~g}$ ) were decarbonated by acidification with $1 \mathrm{~N} \mathrm{HCl}$, rinsed three times with deionized water until the $\mathrm{pH}$ value decreased to around 7 , and dried using a freeze dryer. Finally, the dried samples $(\sim 20 \mathrm{mg}$ per sample) were manually ground, sealed in tin foil, and loaded onto the analyzer for analysis. In a similar manner, TC was measured without $\mathrm{HCl}$ treatment. In order to eliminate the deviation from the weight loss of carbonates, TOC was corrected using the following formula: TOC $(\%)=\mathrm{TOC}_{\text {measured }} \times(12-\mathrm{TC}) /\left(12-\mathrm{TOC}_{\text {measured }}\right)$. Alkanes were measured by GC-MS (Agilent) at State Key Laboratory of Marine Geology (Tongji University) and grain size was measured using Laser Diffraction Particle Size Analyzer (Beckman Coulter LS230, United States). Water content was calculated as follows: water content $=$ (wet weight - dry weight) $/$ wet weight. The age model for this core was established by the planktonic foraminiferal (Globigerinoides ruber) $\delta^{18} \mathrm{O}$ curve (Zhao et al., 2017). Sedimentation rate (SR, unit: $\mathrm{cm} \mathrm{kyr}^{-1}$ ) was estimated by age and the thickness of the sediment column.
Porewater samples were collected on board the ship from sediments using rhizon samplers (Seeberg-Elverfeldt et al., 2005), which were equipped with vacuum syringes. Approximately 5$10 \mathrm{ml}$ volume of pore water was removed from the sediment and filtered with $0.22 \mu \mathrm{m}$ membrane. A total of 28 samples were collected and frozen immediately at $-20^{\circ} \mathrm{C}$ for storage. Nutrient analyses including nitrate, nitrite, ammonium and phosphate were performed on a continuous flow analyzer (AA3, Seal Analytical, Norderstedt, Germany). Sulfate and chloride contents were measured by ion chromatography (ICS-1500; Dionex, CA, United States) at Tongji University (Shanghai, China).

\section{DNA Extraction and 16S rRNA Gene Sequencing}

Bulk DNA was extracted from approximately $0.5 \mathrm{~g}$ sediment of each sampling depth with the FastDNA ${ }^{\circledR}$ spin kit for soil (MP Biomedicals, United States) following a modified version of the manufacturer's protocol. According to the results of a preexperiment, guanidinium thiocyanate (GTC) wash buffer (MP Biomedicals, United States) was used to improve the efficiency of DNA extraction. Sterilized quartz sand was used as control in each DNA extraction process. In total, 35 samples were included in the extraction. Archaeal 16S rRNA gene fragments were amplified using specific primers Arch_524F 5'-barcode-TGY CAG CCG CCG CGG TAA-3' and 958_R 5'-YCC GGC GTT GAV TCC AAT T-3' (Liu et al., 2016; Liu C. et al., 2017; Cerqueira et al., 2017), which cover the V4-5 regions. The V3 and V4 regions of the bacterial $16 \mathrm{~S}$ rRNA genes were amplified using the bacterial universal primers 338F: 5'-ACTCCTACGGGAGGCAGCAG-3' and 806R: 5'-GGACTACHVGGGTWTCTAAT-3' (Fan et al., 2019). PCR reactions were conducted in triplicate in a $20 \mu \mathrm{L}$ reaction volume containing $0.8 \mu \mathrm{l}$ of each primer $(5 \mu \mathrm{M}), 4 \mu \mathrm{l}$ of $5 \times$ FastPfu Buffer, $0.4 \mu \mathrm{l}$ of FastPfu Polymerase, $2 \mu \mathrm{l}$ of $2.5 \mathrm{mM}$ dNTPs, and $10 \mathrm{ng}$ of template DNA. The PCR products were sent to Majorbio Bio-Pharm Technology Co., Ltd. (Shanghai, China) for sequencing.

Briefly, 16S rRNA gene amplicons were extracted from 2\% agarose gels and purified using the AxyPrep DNA Gel Extraction Kit (Axygen Biosciences, Union City, CA, United States) according to the manufacturer's instructions and quantified using QuantiFluor $^{\mathrm{TM}}$-ST (Promega, United States). The sequencing library was prepared using the NEXTFLEX ${ }^{\mathrm{TM}}$ Rapid DNA-Seq Kit (BIOO Scientific Crop., Austin, TX, United States) following the manufacture's recommendations. The purified amplicons were pooled and paired-end $(\mathrm{PE})$ sequenced $(2 \times 250)$ on an Illumina MiSeq platform (Illumina Inc., San Diego, CA, United States) according to standard protocols. The raw reads were deposited into the NCBI Sequence Read Archive (SRA) (PRJNA563932 and PRJNA667744).

\section{Real-Time Quantitative PCR}

Archaeal 16S rRNA genes were quantified by real-time quantitative PCR (PIKO REAL 96, Thermo Fisher Scientific, place, country) with Archaea-specific primers (Arch344F 5'-ACG GGG YGC AGC AGG CGC GA-3' and Arch915R 5'-GTG CTC CCC CGC CAA TTC CT-3') (Casamayor 


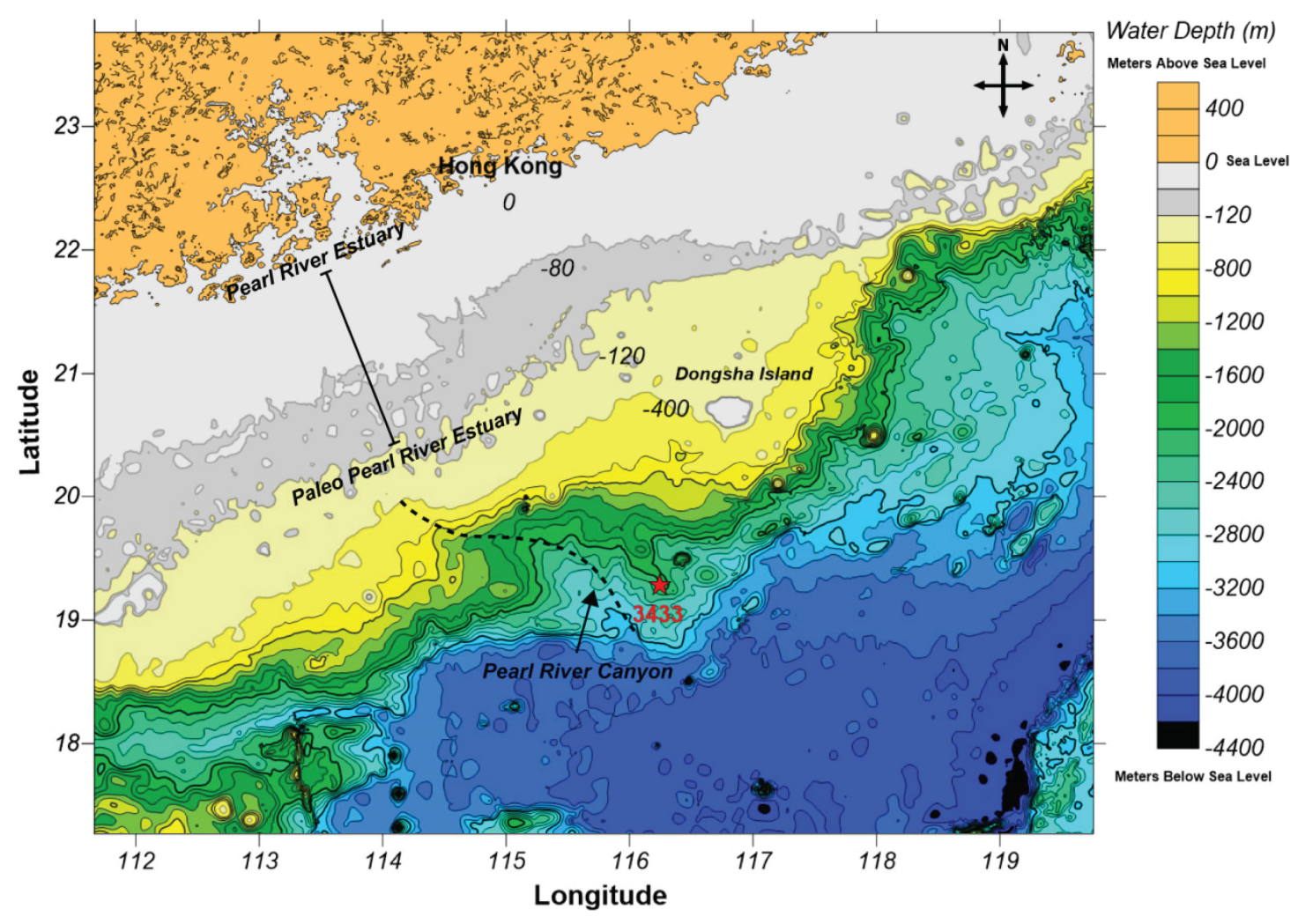

FIGURE 1 | Geomorphologic map of the northern continental margin of the South China Sea. Color bar on the right side represents water depth. The sediment core location is indicated by the red star. The black dotted line is the Pearl River Canyon. The range of Pearl River Estuary is shown by a black solid line.

et al., 2002; Ohene-Adjei et al., 2007) targeting the V3-V5 region of the $16 \mathrm{~S}$ rRNA gene. Each $10 \mu \mathrm{l}$ qPCR reaction solution consisted of $5 \mu$ l SYBR Premix Ex TaqTM II (TaKaRa Bio Co., Kutsatsu, Japan), $1 \mu$ l of template DNA, $0.2 \mu l$ of $1 \mu \mathrm{M}$ each primer, $0.1 \mu \mathrm{l}$ Bovine Serum Albumin (BSA, $20 \mathrm{mg} / \mathrm{mL}$ ) solution (TaKaRa Bio Co., Kutsatsu, Japan) and $3.5 \mu \mathrm{l}$ deionized water. Sterilized water was used as a negative control. The procedures for $\mathrm{qPCR}$ were as follows: $95^{\circ} \mathrm{C}$ for $30 \mathrm{~s} ; 35$ cycles at $95^{\circ} \mathrm{C}$ for $5 \mathrm{~s}, 55^{\circ} \mathrm{C}$ for $30 \mathrm{~s}$, and $72^{\circ} \mathrm{C}$ for 1 min. The qPCR was done in triplicates for each sample. The standard curve was obtained by using five 10 -fold serial dilutions of purified plasmid DNA from the cloned archaeal 16S rRNA gene of Nitrosopumilus maritimus with the primer pair Arch21F and Arch958R (DeLong, 1992). The $R^{2}$ values for the standard curves were greater than 0.98 and the amplification efficiencies were between 85 and $88 \%$. qPCR results were rejected if the post-amplification melt curves showed evidence of primer dimers.

\section{Data Processing and Statistical Analysis}

Raw Illumina fastq files were de-multiplexed, quality-filtered and analyzed using QIIME (Quantitative Insights into Microbial Ecology, version 1.9.1). Chimeric reads were filtered using UCHIME (Edgar et al., 2011) and Operational Taxonomic Units (OTUs) at $97 \%$ sequence similarity was done using UPARSE (version $7.1^{1}$ ). The taxonomy of each OTU was assigned using the RDP Classifier ${ }^{2}$ against the Silva (SSU123) database using a confidence threshold of $70 \%$. All samples were normalized to the lowest number of sequences (19,195 reads), since uneven sequencing depth could affect microbial diversity estimates. Rarefaction curves indicated that sufficient reads were obtained for robust statistical analysis (Supplementary Figure 1).

Rarefaction curves, richness estimators (Chao) and diversity estimators (Shannon index) were calculated with Mothur software (version 1.34.4) (Schloss et al., 2009). Non-metric multidimensional scaling analysis (NMDS) was used to determine the degree of dissimilarity between pairs of archaeal communities using the Bray-Curtis distance method. NMDS and one-way analysis of similarity (ANOSIM: permutations = 999) were executed with the vegan package in $\mathrm{R}$ version 3.5.1. Visualization was handled in $\mathrm{R}$ using the ggplot2 graphics package (Wickham, 2011).

An estimate of the absolute abundance of 16S rRNA gene copies of SCG, MG-I, and Thermoprofundales per gram of sediment was calculated by multiplying the absolute archaeal $16 \mathrm{~S}$ rRNA gene abundance (obtained by qPCR) by their respective relative abundance from 16S rRNA gene sequencing (Lou et al., 2018; Elovitz et al., 2019; Dorsaz et al., 2020).

\footnotetext{
${ }^{1}$ http://drive5.com/uparse/

${ }^{2}$ http://rdp.cme.msu.edu/
} 


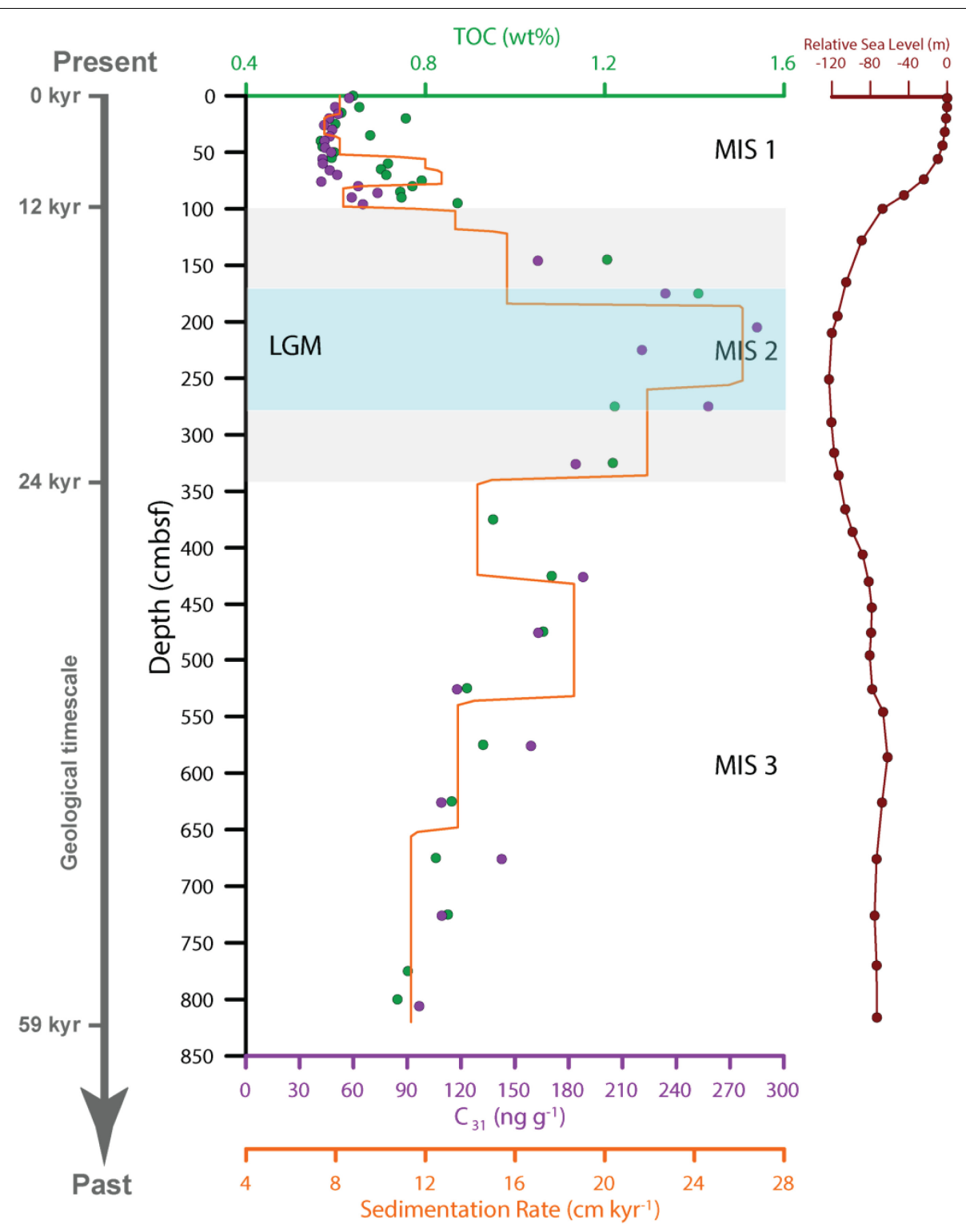

FIGURE 2 | The depth profiles of total organic carbon (TOC), n-alkane $C_{31}$, and sedimentation rate. The geological timescale (59 kyr-present) is shown on the right. The Relative Seal Level is from Higginson et al. (2003). Samples were assigned to MIS 1, MIS 2, and MIS 3 according to the age model established by (Zhao et al., 2017). LGM, Last Glacial Maximum.

Redundancy analysis (RDA) was conducted using PRIMER v6.1.16 (Plymouth Routines In Multivariate Ecological Research, PRIMER-E. Ltd., New Zealand) to examine the relationships between archaeal communities and environmental parameters. The distance matrix of archaeal groups, as response variables, was calculated using the Bray-Curtis method. A stepwise method with $R^{2}$ value was applied for the selection of environmental factors. The statistical significance of the RDA was further tested using the Monte Carlo permutation test (999 permutations).

To examine associations between archaeal taxa, we analyzed pairwise correlations of the relative abundance of archaeal OTUs using Extended Local Similarity Analysis (eLSA) (Xia et al., 2011). OTU abundance data were filtered including a mean minimum occurrence of 2 OTUs per sample and the ratio of empty less than $1 / 3$. $P$-values were estimated using the "perm" approach and "percentile Z" in the setting was used to normalize data (Xia et al., 2013). False discovery rates (FDR Q-values) were calculated to estimate the likelihood of false positives (Storey, 2003). The whole sediment column was separated into two parts: samples in MIS 1 and samples in MIS 2 and MIS 3, based on their similarity. OTUs with significant correlations $(P \leq 0.05$ and $Q \leq 0.01)$ were visualized in Cytoscape (v3.7.0) (Shannon et al., 2003) together with an attribute table of taxonomy.

A phylogenetic tree of AOA based on the 16S rRNA gene was inferred with QuickTree (Howe et al., 2002) using the neighborjoining method with 1000 bootstrap replicates. Numbers at 
branch nodes refer to bootstrap values. Sequences used for creating the phylogenetic tree include AOA sequences from MD12-3433, the corresponding best Blast hits from NCBI, published MG-I subgroup sequences (Durbin and Teske, 2010) and MG-I sequences from the water column of the South China Sea (Liu H. et al., 2017). Euryarchaeota sequences were used as an outgroup. Visualization and annotation were conducted in $\mathrm{R}$ software (V.3.5.1).

\section{RESULTS}

\section{Pore Water Chemistry}

Chloride and sulfate were measured immediately after the pore water samples arrived at the home laboratory (Tongji University). Nitrate, nitrite, ammonium, and phosphate were measured in a later time at Tongji University. These parameters tended to be unstable during measurements and the pore water samples were transferred between two different labs, and may not have been preserved appropriately during storage. Thus, only chloride and sulfate were reported in this study (Supplementary Figure 2).

\section{Sedimentation Rate, TOC and n-Alkane $\mathrm{C}_{31}$}

The sedimentation rate varied between 11.4 and $18.6 \mathrm{~cm} \mathrm{kyr}^{-1}$ during MIS 3 and showed a general increasing trend with younger sediments. On average, the sedimentation rates were $14.0 \pm 2.7 \mathrm{~cm} \mathrm{kyr}^{-1}$ in MIS 3, $19.6 \pm 4.8 \mathrm{~cm} \mathrm{kyr}^{-1}$ in MIS 2, and $9.2 \pm 1.9 \mathrm{~cm} \mathrm{kyr}^{-1}$ in MIS 1 (Figure 2). The sedimentation rates in the three MISs differed significantly as determined by independent-sample two-tailed $t$-test $(p<0.001)$.

The TOC and n-alkane $\mathrm{C}_{31}$ content exhibited similar variations as the sedimentation rate and a significant positive linear correlation was observed (Supplementary Figure 3). The TOC content varied between 0.73 and 1.08 wt $\%$ in MIS 3, increased to its maximum value of $1.41 \mathrm{wt} \%$ at $1.75 \mathrm{~m}$ in MIS 2 , and decreased to its minimum value of $0.57 \mathrm{wt} \%$ during MIS 1. The n-alkane $\mathrm{C}_{31}$ content, a terrestrial biomarker, varied from 96.7-188.1 ng/g in MIS 3, increased to a maximal value of $285 \mathrm{ng} / \mathrm{g}$ in MIS 2, and was reduced to its minimum value of $42.1 \mathrm{ng} / \mathrm{g}$ during MIS 1 . The average TOC and n-alkane $\mathrm{C}_{31}$ values during MIS $2(1.26 \pm 0.10 \mathrm{wt} \%$ and $224.1 \pm 45.44 \mathrm{ng} / \mathrm{g}$, respectively) were significantly higher $(P<0.01)$ than those in MIS $1(0.68 \pm 0.09 \mathrm{wt} \%$ and $50.85 \pm 8.79 \mathrm{ng} / \mathrm{g}$, respectively) and MIS 3 (0.89 $\pm 0.11 \mathrm{wt} \%$ and $132 \pm 33.45 \mathrm{ng} / \mathrm{g}$, respectively). Mean TOC and n-alkane $\mathrm{C}_{31}$ values during MIS 3 were significantly higher than those in MIS $1(p<0.01)$. The contrast between MIS 1 and MIS 2 was sharper than the transition between MIS 2 and MIS 3, which correlates with more drastic changes in sea level between the MIS 1 and MIS 2 periods. Overall, the sedimentation rate, TOC and n-alkane $\mathrm{C}_{31}$ were highest in MIS 2 , reflecting maximal terrestrial input.

\section{Archaeal Community Structure}

16S rRNA Illumina tags were clustered into 793 unique OTUs, with an average of 175 OTUs per sample. Good's coverage values exceeded $99.8 \%$, which is indicative of a high level of diversity coverage in the samples. Alpha diversity indices were calculated using Chao 1 and Shannon (Supplementary Figure 4). Whereas no obvious trend for the Shannon index was observed between the three MISs, there was gradual increase in Chao 1 richness from MIS 3 to MIS 2 and a gradual decrease from MIS 2 to MIS 1.

Lokiarchaeota and Bathyarchaeota were consistently the predominant archaeal groups in the core (Figure 3). Lokiarchaeota accounted for more than $50 \%$ of the archaeal community and Bathyarchaeota accounted for approximately $14 \%$. Thaumarchaeota were also significant components in the samples. MG-I (Nitrosopumilales), the major Thaumarchaeota lineage in oceans, accounted for over $60 \%$ of archaea in the surface sediments (i.e., $0-5 \mathrm{~cm}$ ) and the mean was $11.8 \pm 14.5 \%$ in MIS 1 , but only $1.67 \pm 0.56 \%$ in MIS 2 and MIS 3. MBGA was most prevalent in MIS 1, accounting for $4.34 \%$ of the archaeal population on average. A marked decrease in MG-I was observed in MIS 2 and MIS 3; in contrast, the relative abundance of Thermoprofundales and Hadesarchaeota was higher in sediments deposited during these two stages. The latter two groups on average comprised $10.53 \pm 2.87$ and $5.71 \pm 6.54 \%$ of total archaea in MIS 2 and MIS 3, respectively, which were much higher than their presence in MIS 1 (2.70 $\pm 1.89 \%$ for Thermoprofundales and $1.02 \pm 0.94 \%$ for Hadesarchaeota). The minor Thaumarchaeota group SCG (Nitrososphaerales) varied from 0.05 to $3.45 \%$ and reached its maximum abundance at $175 \mathrm{cmbsf}$.

Based on non-metric multidimensional scaling (NMDS) analysis (Figure 4), MIS 1-derived samples clustered separately from samples from the other periods. This was also supported by pairwise ANOSIM tests (Figure 3).

Redundancy analysis (RDA) was used to identify environmental factors that correlate with the archaeal community structure. As displayed in Supplementary Figure 5, the first and second canonical axes represented $79.9 \%(26.2 \%$ of total) and $19.5 \%$ (6.4\% of total) of the total variance observed, respectively. RDA1 separated MIS 1 archaeal communities from MIS 2 and MIS 3 communities. The n-alkane $\mathrm{C}_{31}(p<0.01)$ and TOC $(p<0.01)$ correlated significantly with the archaeal communities and were highest in MIS 2 and MIS 3. While TOC was significantly correlated with Thermoprofundales and total nitrogen correlated best with SCG, n-alkane $\mathrm{C}_{31}$ was closely related to Methanomicrobia, Ca. Poseidoniales, and Hadesarchaeota. Additionally, MG-I and MGBA negatively correlated with TOC and n-alkane $\mathrm{C}_{31}$. Notably, Lokiarchaeota and Bathyarchaeota, the two most abundant groups in the sediment core, did not correlate with TOC or n-alkane $\mathrm{C}_{31}$.

\section{The qPCR Abundance of 16S rRNA Genes of Archaea and AOA}

The archaeal 16S rRNA gene copy number per gram of wet sediment (/g.w.sdmt) ranged from $1.89 \times 10^{5}$ to $2.58 \times 10^{6}$ in MIS 3, and it gradually increased in MIS 2 followed by a decrease in MIS 1 (Supplementary Figure 6A). The highest gene copy number $\left(8.39 \times 10^{6} /\right.$ g.w.sdmt $)$ was found at 175 cmbsf, consistent with the highest concentration of TOC. Overall, the mean archaeal $16 \mathrm{~S}$ rRNA gene copy numbers 


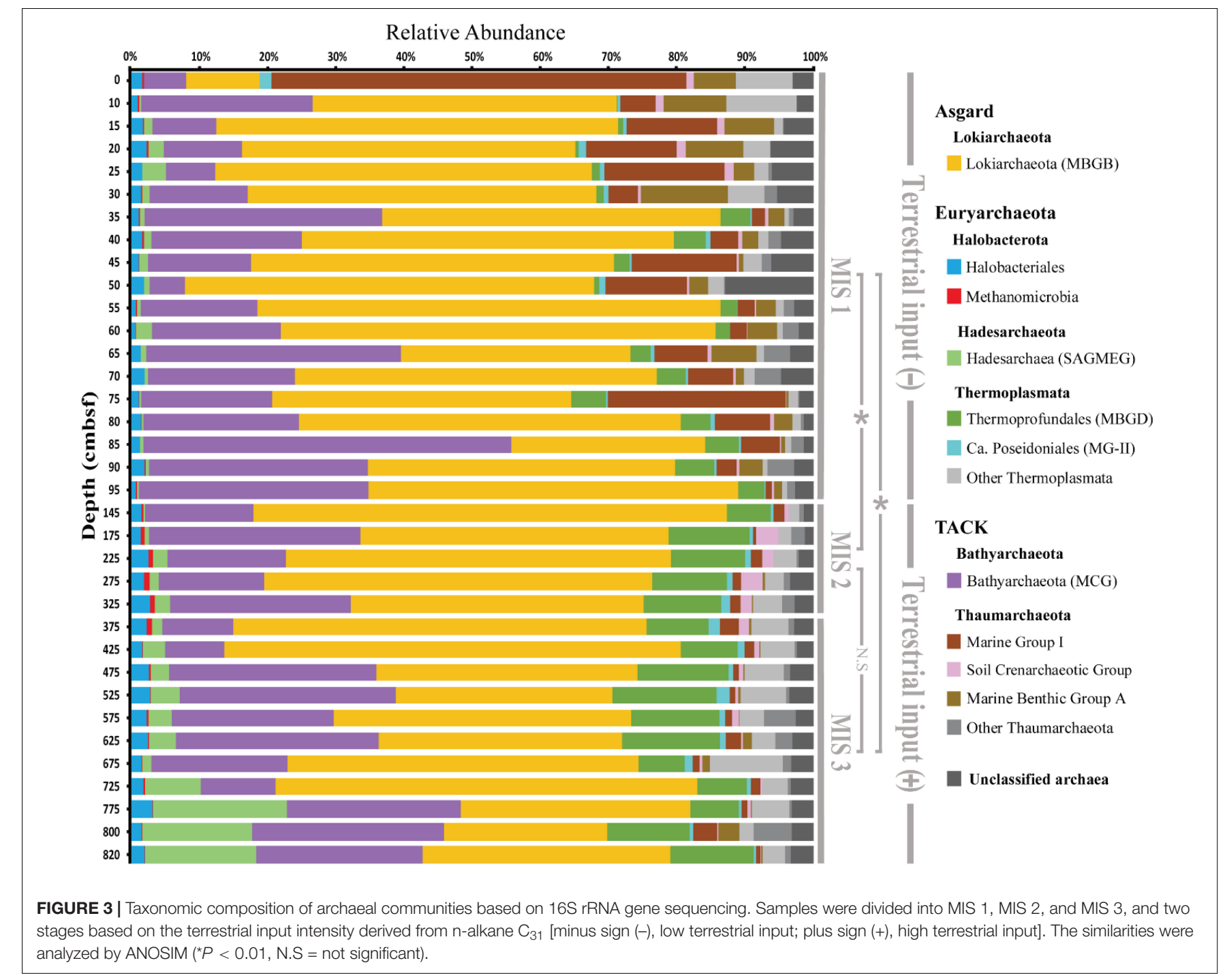

were $8.32 \times 10^{5} /$ g.w.sdmt in MIS $1,4.27 \times 10^{6} /$ g.w.sdmt in MIS 2 and $1.02 \times 10^{6} /$ g.w.sdmt in MIS 3. The SCG $16 \mathrm{~S}$ rRNA gene copy number showed a similar trend with that of archaea but was orders of magnitude lower. The SCG 16S rRNA gene copy number varied between $6.46 \times 10^{2} /$ g.w.sdmt and $1.70 \times 10^{4} /$ g.w.sdmt (Supplementary Figure 6B). While a large variation occurred between 50 and $100 \mathrm{~cm}$ during MIS 1 , it reached the maximum value of $3.31 \times 10^{5} /$ g.w.sdmt at $175 \mathrm{cmbf}$ in MIS 2 and then decreased gradually to the lowest value of $1.82 \times 10^{3} /$ g.w.sdmt in MIS 3. On average, the SCG gene copy number was $3.63 \times 10^{3} /$ g.w.sdmt in MIS $1,7.59 \times 10^{4} /$ g.w.sdmt in MIS 2 and $7.41 \times 10^{3} /$ g.w.sdmt in MIS 3 .

MG-I gene copy number exhibited a different pattern. MGI gene copy number showed a decreasing trend in MIS 1, with three peaks at 35, 65 and $85 \mathrm{cmbsf}$. It decreased downward into MIS 2 and MIS 3 with the lowest value of $2.14 \times 10^{3} /$ g.w.sdmt at $475 \mathrm{cmbsf}$ in MIS 3. On average, the MG-I gene copy number was $5.50 \times 10^{4} /$ g.w.sdmt in MIS 1, $4.79 \times 10^{4} /$ g.w.sdmt in MIS 2 and $1.48 \times 10^{4} /$ g.w.sdmt in MIS 3 .

\section{Impact of Terrestrial Input on SCG and Thermoprofundales}

Five SCG OTUs with the highest relative abundances (OTU321, OTU463, OTU650, OTU530, and OTU593) showed a drastic increase during MIS 2 (Supplementary Figure 7A), suggesting that they may be derived from terrestrial sources. These OTUs displayed a consistent pattern of fluctuation, suggesting that terrestrial input may be a significant factor shaping their distribution. The distinct patterns of SCG OTUs present in MIS 1 and MIS 3 may indicate varying influence of different climatic factors on SCG sedimentation, in situ growth, and/or preservation during periods of high and low terrestrial input. Additionally, the absolute abundance of SCG was significantly correlated with $\mathrm{n}$-alkane $\mathrm{C}_{31}(R=0.61)$, TOC $(R=0.63)$, and sedimentation rate $(R=0.44)$ in the sediment core, suggesting that it is of terrestrial origin (Supplementary Figure 8A).

SCGs in marine sediments consisted of OTUs $-303,-42$, $-453,-593,-463,-321,-74,-193,-650,-783,-530$, $-594,-230,-494,-274$, and -45 . Interestingly, phylogenetic 


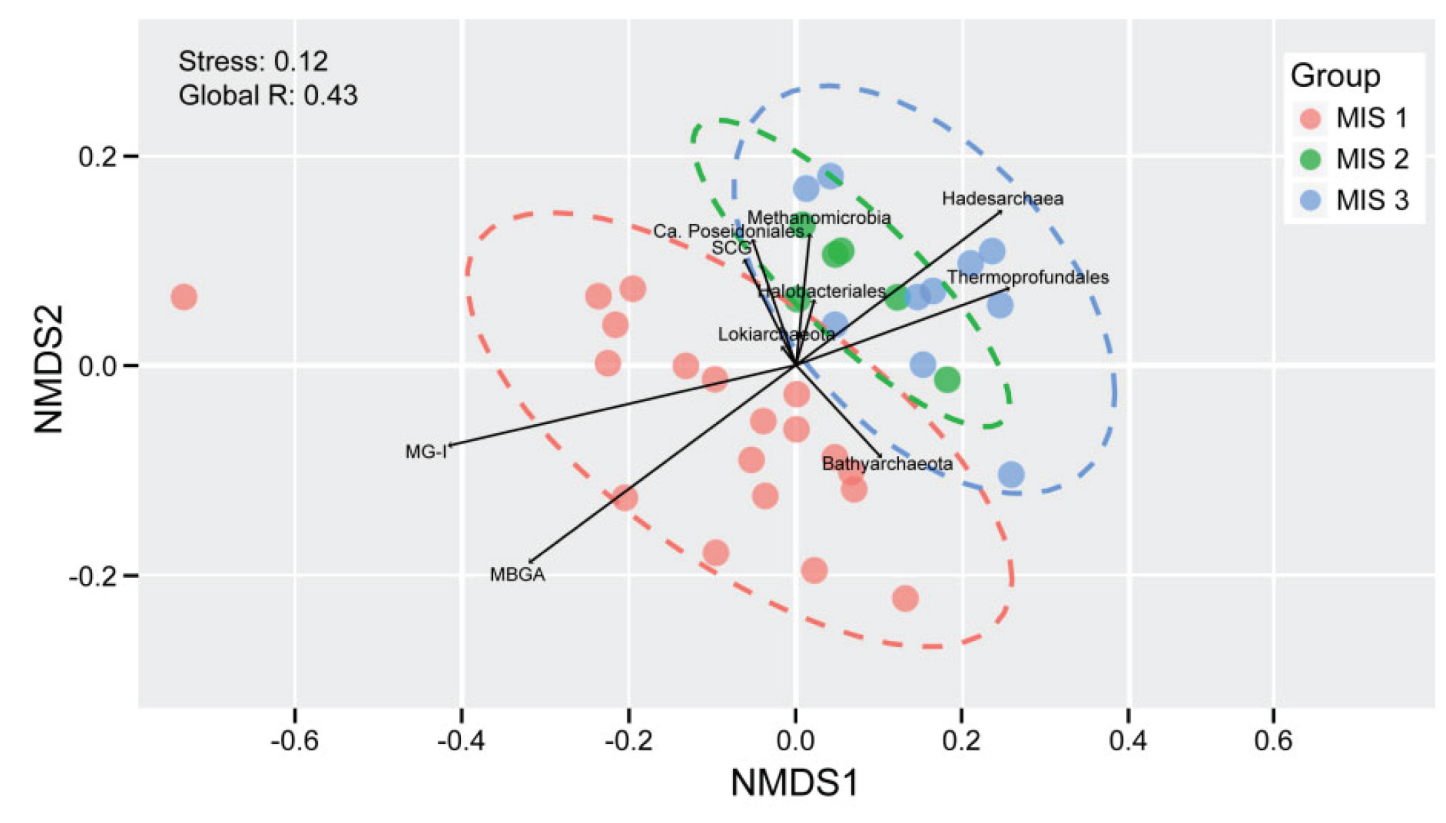

FIGURE 4 | The archaeal community structure in relationship to MIS stages by the NMDS analysis based on Bray-Curtis dissimilarities. Each dot represents a sample and the colors indicated different groups. Ellipses denote 95\% confidence intervals.

analysis demonstrated that SCG sequences obtained from marine and terrestrial environments were not phylogenetically distinct (Supplementary Figure 9).

The absolute abundance of Thermoprofundales also showed significant positive correlations with n-alkane $C_{31}$ $(R=0.54)$, TOC $(R=0.58)$, and sedimentation rate $(R=0.51)$ (Supplementary Figure 8B). Further investigation showed that the seven most abundant Thermoprofundales OTUs exhibited a marked increase in MIS 2-derived samples (Supplementary Figure 7B). The results indicated that Thermoprofundales was significantly affected by terrestrial input. Overall, the distributional patterns of Thermoprofundales OTUs were similar to SCG OTUs, but with orders of magnitude higher abundance.

Interestingly, the ratio of sulfate to chloride was consistently around 0.05 in the MIS 1-derived sediments (Supplementary Figure 2), suggesting that there was no significant loss of sulfate through dissimilatory sulfate reduction. The ratio decreased gradually with increasing depth in MIS 2- and MIS 3-derived sediments, suggesting sulfate reduction in the deeper sediments. However, no known sulfate-reducing archaea (SRA) were found. The profiles could be caused by sulfate-reducing bacteria (SRB) or unknown SRA. We examined the bacterial data and indeed found presence of SRB in all the sediment layers (present in very low abundance). However, unlike archaea, the distributional patterns of bacteria, including SRB, were unrelated to the terrestrial input (Supplementary Figure 10).

\section{Network Analysis of Archaeal Communities}

Both ANOSIM analysis and NMDS ordination analysis clearly separated samples into two groups: MIS 1 and MIS 2 - MIS 3
(Figures 3, 4). As such, we constructed archaeal co-occurrence networks to investigate the correlations between the OTUs within MIS 1 (Figure 5A), and OTUs shared between MIS 2 to MIS 3 (Figure 5B). A highly connected cluster (module) of MG-I OTUs was observed in the MIS 1 group, whereas only four MGI OTUs with two degrees were observed in the MIS 2 - MIS 3 group. In contrast, SCG OTUs exhibited an opposite pattern. SCG OTUs were less connected in the MIS 1 group but intensively connected within the group and with benthic groups such as Bathyarchaeota and Thermoprofundales in the MIS 2 - MIS 3 group. Additionally, Methanomicrobia were more intensely connected in the MIS 2 - MIS 3 group compared to the MIS 1 group. Lokiarchaeaota, one of the "Asgard archaea," showed less connection to other archaeal groups although they were present in high abundance, which is apparently contradictory to the syntrophic nature of the only lab-cultivated member of the group, 'Candidatus Prometheoarchaeum syntrophicum' (Imachi et al., 2020). However, since co-correlations were not computed between archaea and bacteria, it is possible that the Lokiarchaeota could be syntrophic with one or more bacteria.

\section{DISCUSSION}

\section{Geological Framework of the Pearl River Submarine Canyon Sediments}

The sediment core from the Pearl River Submarine Canyon region of the South China Sea (Figure 1) represented three MISs, which were correlated with changes in sedimentation rate, TOC and the terrestrial n-alkane $\mathrm{C}_{31}$ (Figure 2). MIS 2, the glacial period, displayed the highest levels of TOC, n-alkane $\mathrm{C}_{31}$ and 

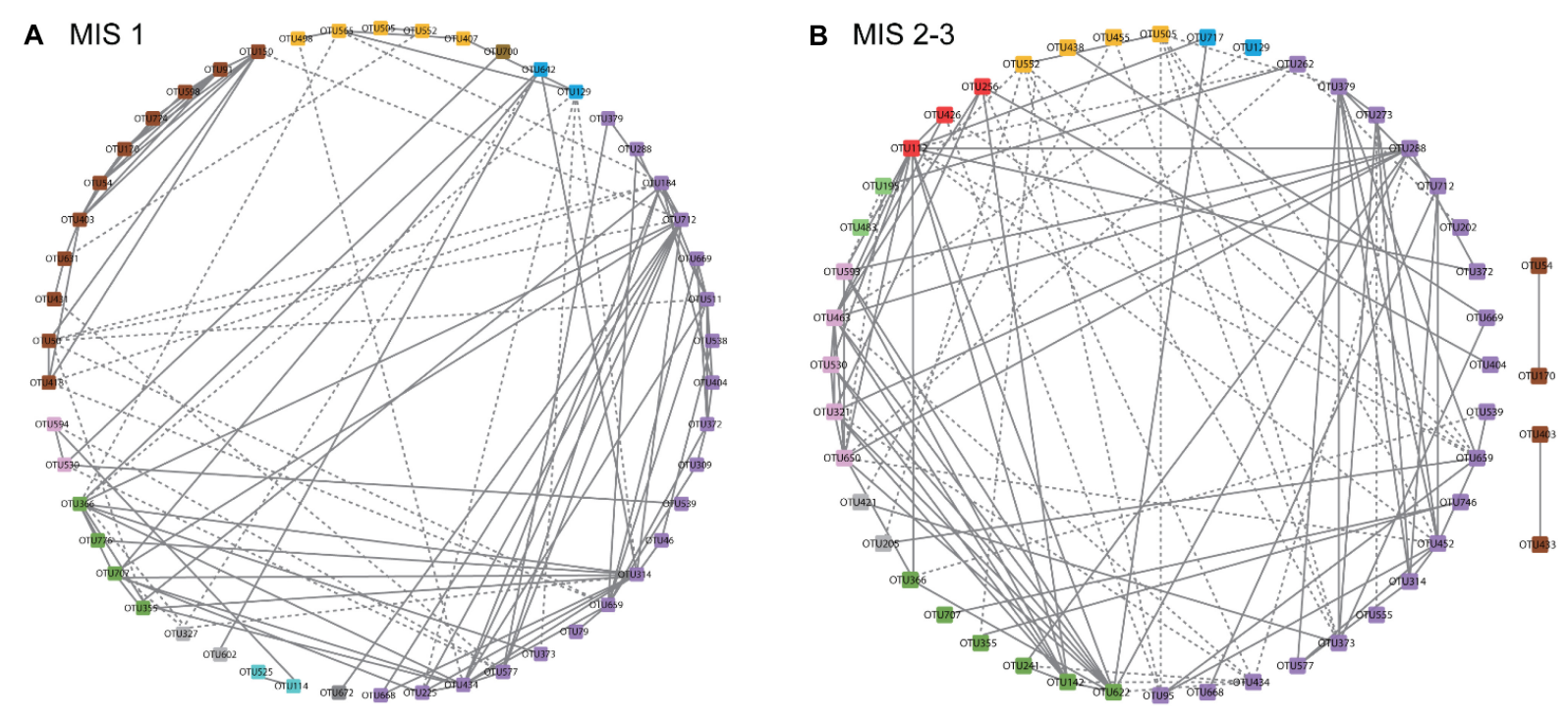

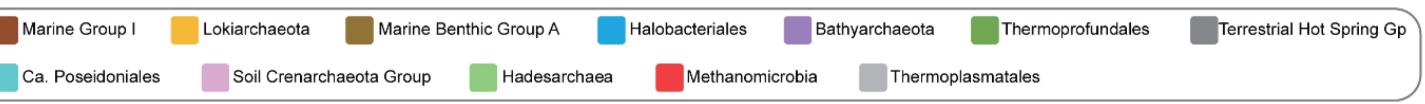

FIGURE 5 | Correlation network analysis of archaeal communities. Each node represents an OTU and edges are defined based on the correlation between abundance profiles across samples in MIS 1 (A) and MIS 2-MIS 3 (B). Nodes with significant correlations are connected, with solid and dotted lines representing positive and negative correlations, respectively. Nodes are colored based on taxonomy.

sedimentation rate while MIS 1 (Holocene) displayed the lowest of the three parameters. High enrichment of organic carbon could be caused by either an increased input of organic matter or increased preservation in anoxic marine sediments (Stein, 1990). The significant positive correlation between organic carbon and sedimentation rate (Supplementary Figure 3 ) suggests that the former is the more important, although fine-grained and reducing environments could contribute to the preservation of organic matter (Müller and Suess, 1979). Several studies have shown that $\mathrm{OM}$ can be stabilized and can sustain long-term preservation in marine sediments by binding with metal ions and clay minerals (Curry et al., 2007; Blattmann et al., 2019).

Notably, the greatest decrease in relative sea level was observed in the transition from MIS 2 to MIS 1 compared to MIS 3 to MIS 2. The observations made in MIS 2 support previous evidence that global cooling is associated with accumulation of organic carbon in the deep sea, and OM fluxes to the deep sea have been estimated to be $\sim 50 \%$ higher during glacial maxima than during interglacials (Cartapanis et al., 2016). Moreover, there have been prior reports of a link between global cooling and accelerated terrestrial sedimentation during the late Cenozoic Era (Molnar, 2004), though this relationship has been challenged (Willenbring and von Blanckenburg, 2010). Additionally, the paleo Pearl River Estuary extended outward and contracted inward with the large eustatic sea-level fall and rise (Figure 1). Although different evolutionary models of the Pearl River Estuary have been proposed (Wu et al., 2007; Tang et al., 2010), they agree that geographical changes in the estuarine system altered the terrestrial input, sedimentary processes or depositional environments. Understanding of the geological framework is important for interpreting changes in the archaeal community structure in the Pear River Submarine Canyon sediments (see below).

\section{The Impact of Terrestrial Input on Archaeal Communities}

By profiling the vertical distribution of archaeal communities and cross-referencing environmental footprints conserved in the sediment, our understanding of the factors that shape archaeal structure is improved. For example, while $\mathrm{pH}$ and temperature have been deemed important regulators of community structure in non-saline environments (Cole et al., 2013; Hedlund et al., 2016; Wen et al., 2017), organic carbon concentration has been shown to be an important factor shaping archaeal community structure in marine sediments (Durbin and Teske, 2012; Learman et al., 2016). In other deep-sea ecosystems, bottom water temperatures and trophic resources including organic substrates (Danovaro et al., 2016) at least partially drive habitat preferences. Our results show that the alteration of archaeal community structure in marine sediments is associated with terrestrial input, either directly, by bringing in compounds such as longchain $\mathrm{n}$-alkanes derived from epicuticular waxes of vascular plant leaves (Bi et al., 2005), which may stimulate or support the growth of some lineages, or indirectly, by changing the depositional conditions.

In particular, the occurrence of the highest total abundance of the archaeal 16S rRNA gene in MIS 2-derived samples (Supplementary Figure 6A) can be explained in detail. One explanation is that fermentation of a large amount of terrestrial 
organic matter occurred in situ, which provided energy for the growth of archaea that may have participated in the fermentation process. Recent research showed that fermentation-related genes encoding multiple fermentation pathways were found in marine sediments (Zinke et al., 2019). Additionally, fermentation pathways have been found in genomes of Thermoprofundales (Zhou et al., 2019) and Lokiarchaeota (Orsi et al., 2020). The recently cultivated member of the Lokiarchaeota, 'Candidatus Prometheoarchaeum syntrophicum', has been shown to ferment amino acids (Imachi et al., 2020). Some archaeal lineages are capable of degrading refractory organics (He et al., 2016; Yu et al., 2018), which are further utilized by other organisms.

Another explanation is that the increased supply of terrigenous matter may also bring in nutrients that stimulated phytoplankton growth, which produced rich sources of labile organic carbon such as amino acids. That labile carbon pool may have settled rapidly to the sea floor due to the high sedimentation rate and became trapped in fine-grained sediments (Curry et al., 2007), with labile fractions used by heterotrophic microbes, including archaea.

The low-abundance archaeal group SCG, important AOA that dominate soil archaeal communities (Bates et al., 2011), was strongly associated with long-chain n-alkane $C_{31}$ (Supplementary Figure 8A), supporting its terrestrial origin (Seki et al., 2003). In accordance with this hypothesis, SCG OTUs from this study exhibited a high similarity with SCG from terrestrial environments based on phylogenetic analysis (Supplementary Figure 9). While fluctuations were apparent across all SCG OTUs throughout the sediment core, all five SCG OTUs $(321,463,650,530$, and 593) simultaneously increased dramatically during the Last Glacial Maximum, when terrestrial input was at its maximum (Supplementary Figure 7A), which would also transport a larger amount of TerrOC into the ocean than during interglacial periods.

The presence of terrestrial SCG in marine sediment may also suggest that they survive and remain active after being transported from soil. Several studies have shown that SCG have diverse metabolisms, including autotrophy (Stieglmeier et al., 2014) and heterotrophy (Hallam et al., 2006; Mußmann et al., 2011). An in situ cultivation experiment in deep-sea sediments indicated SCG was among the most abundant group in the initial archaeal community and they still existed after 405 days (Takano et al., 2010). RDA analysis showed that SCG was the lineage most closely related to total nitrogen (Supplementary Figure 5), which might indicate its role in metabolizing organic nitrogen (Di et al., 2010; Levičnik-Höfferle et al., 2012; Lehtovirta-Morley et al., 2016; Abby et al., 2018). Network analysis showed not only intimate interactions within SCG OTUs but also with other benthic groups such as Bathyarchaeota, Thermoprofundales, and Methanomicrobia (Figure 5B). Such interactions could result from metabolic associations. For example, the production of urea by Bathyarchaeota (Pan et al., 2020) could be used by SCG (Tourna et al., 2011) and the synthesis of cobalamin by Nitrososphaera (Lu et al., 2020), a group of SCG, could stimulate growth of cobalamin-dependent lineages. However, we cannot exclude the possibility that interactions could be caused by their similar environmental niches. Interestingly, SCG have been reported to grow in the absence of nitrification (Jia and Conrad, 2009).

Another intriguing possibility for the existence of SCG in sediment samples and enrichment in MIS 2-derived sediments is their preference for high ammonia concentrations. It has been reported that SCG prefers ammonia-rich environments (Prokopenko et al., 2006; Tourna et al., 2011). MIS 2-derived sediments received a significant increase in organic matter (Figure 2), and a large amount of ammonium could be produced due to the ammonification and mineralization of the organic matter (Prokopenko et al., 2006). Further research should be undertaken to investigate the activity of the SCG lineage in marine sediments considering its potential roles in the nitrogen and carbon cycles.

16S rRNA gene copy numbers of Thermoprofundales, showed significant positive correlation with TOC, n-alkane $\mathrm{C}_{31}$, and sedimentation rate, similar to SCG (Supplementary Figure 8B). Although Thermoprofundales were initially found in marine sediments, they are spread across a wide range of terrestrial habitats including soil, wetland soil, and inland lakes (Jiang et al., 2008; Zhou et al., 2019). The observed increase of Thermoprofundales in MIS 2 may partly be explained by the input of terrestrial Thermoprofundales lineages along with enhanced terrestrial input. In line with this, numerous subgroups of Thermoprofundales were found in both saline and non-saline environments (Zhou et al., 2019). Seven Thermoprofundales OTUs (OTU142, OTU355, OTU384, OTU707, OTU622, OTU366, and OTU776) closely tracked terrestrial input (Supplementary Figure 7B). Another possibility is that Thermoprofundales abundance may be indirectly impacted by terrestrial TOC. Indeed, this is in keeping with research that indicates the critical role of Thermoprofundales in the sedimentary carbon cycle (Lloyd et al., 2013; Vigneron et al., 2014; Zhou et al., 2019).

Although Lokiarchaeota were identified as the dominant archaea with 50\% representation, redundancy analysis revealed that these organisms were not correlated with organic carbon or n-alkane $\mathrm{C}_{31}$ (Supplementary Figure 5). The cultivated member of the Lokiarchaeota is extremely slow-growing in lab cultures (Imachi et al., 2020) and consequently they may be less sensitive to organic carbon. Similarly, Bathyarchaeota, though counting for a large proportion (14\%) of the total archaeal population, did not show significantly correlations with organic carbon or n-alkane $C_{31}$, also likely due to their slow growth (Yu et al., 2018).

The sources of MG-I in Pearl River Submarine Canyon sediments may be complicated. MG-I recovered mainly from marine sediments include $\varepsilon$ (epsilon), $\zeta$ (zeta), $\theta$ (theta), $\eta$ (eta), $\kappa$ (kappa), $v$ (upsilon) and $\iota$ (iota) subgroups, whereas $\gamma$ (gamma), $\delta$ (delta) and $\beta$ (beta) subgroups are usually identified in water columns and the $\alpha$ (alpha) subgroup is found in both water column and sediment (Durbin and Teske, 2010; Lauer et al., 2016). For example, MG-I subgroups $\varepsilon, \kappa$, and $v$ are predominant in the subseafloor sediments at ODP Site 1225 (Lauer et al., 2016). MG-I populations shifted from multiple subgroups to the dominance of subgroups $v$ and $\eta$ as the sediment depth increases in the South Pacific Gyre (Durbin and Teske, 2010). Our results showed two distributional patterns of MG-I subgroups: the $\varepsilon-\zeta-\theta$ 


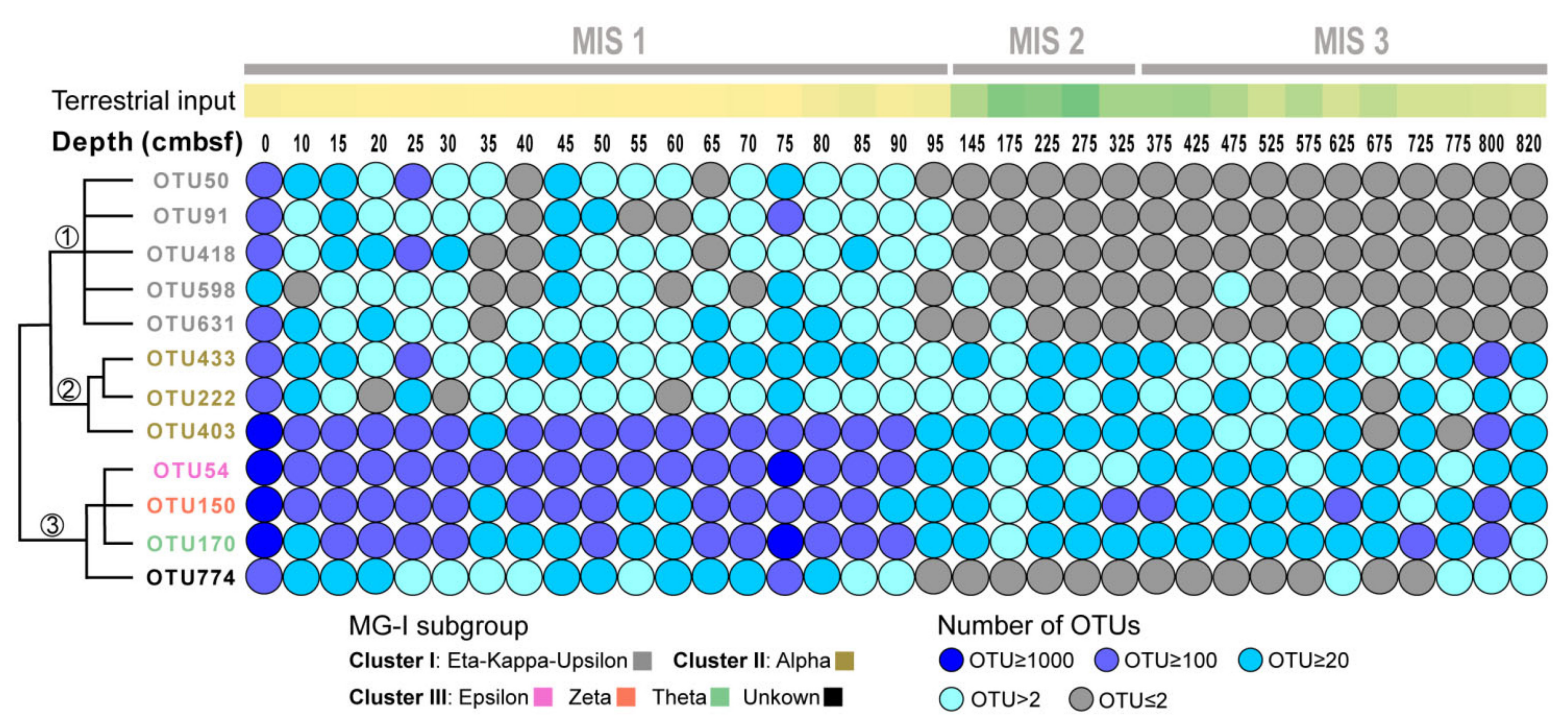

FIGURE 6 | The depth profiles of 12 MG-I OTUs having the highest mean abundance. The color bar above represents the intensity of terrestrial input (yellow: low; green: high). Colored squares on the bottom left represent different MG-I subgroups. Circles in different colors on the bottom right represent the number of OTUs identified. The cluster tree on the left was simplified schematic of evolutionary relationship according to the phylogenetic tree (Supplementary Figure $\mathbf{9}$ ).

subgroups were present across all depth intervals and the $\eta$ - $v$ subgroups mainly existed in the MIS 1 stage. The $\alpha$ subgroup may be a mixture of planktonic or benthic MG-I populations (Figure 6), whose presence is likely linked to the availability of oxygen or nitrate in the sediment porewater (Jorgensen et al., 2012; Lauer et al., 2016; Hiraoka et al., 2020).

MBG-A, a sister group of MG-I, mainly existed in the MIS 1-derived sediments and negatively correlated with the terrestrial biomarker n-alkane $\mathrm{C}_{31}$ (Supplementary Figure 5). Methanomicrobia, dominant in methane-containing sediments (Hamdan et al., 2013), showed a positive correlation with terrestrial input. Depth-related increases in the abundance of Hadesarchaeota have been previously characterized in the South China Sea (Cui et al., 2016) and it exhibited a weak positive correlation with terrestrial input. Ca. Poseidoniales is the dominant planktonic archaeal group in ocean surface waters (Zhang et al., 2015; Rinke et al., 2019) and the lineage showed a weak correlation with terrestrial signal, suggesting pelagic archaea could be trapped with advanced sedimentation.

\section{CONCLUSION}

This study offers a unique look at archaeal communities in a deepsea sediment column spanning over $59 \mathrm{k}$ years in the Pearl River Submarine Canyon. While it is well-known that archaea in deep sea ecosystems play critical roles in biogeochemical cycling, much remains unknown about their specific metabolic capacities and environmental adaptation in deep sea sediments. In addition to broad characterization of a sediment core, this paper provided an in-depth analysis of diverse archaeal groups in marine sediments in the context of terrestrial organic input in the South China Sea. The SCG archaea, though a minor group, revealed high correlation with terrestrial input, which may be a consequence of its terrestrial origins coupled with high sedimentation of organic carbon. MG-I, many of which can be indigenous AOA in marine environments, may participate in nitrogen cycling in the upper layer of sediments. Terrestrial input correlated negatively with MG-I and may insert adaptive pressures to the group. Thermoprofundales may be directly impacted by terrestrial input or indirectly influenced via organic carbon. Additionally, Hadesarchaeota, and MBGA could also be affected by terrestrial input directly or directly.

These results demonstrate that composition of benthic archaea in the South China Sea may be controlled by glacial-interglacial cycles that control terrestrial organic input, providing a plausible link between global climate cycles and microbial population dynamics in deep-sea marine sediments. Though genomic analysis provided important findings, the broad metabolic capacities of some of these archaeal groups are lacking and their roles in deep sea sediments should be pursued.

\section{DATA AVAILABILITY STATEMENT}

The datasets presented in this study can be found in online repositories. The names of the repository/repositories and accession number(s) can be found in the article/Supplementary Material.

\section{AUTHOR CONTRIBUTIONS}

DL, PW, WX, and CZ contributed to experimental design. DL, WX, and JL completed laboratory work. DL contributed to bioinformatics work. DL wrote the manuscript. $\mathrm{BH}, \mathrm{PW}, \mathrm{WX}, \mathrm{TP}$, and $\mathrm{CZ}$ contributed to the writing, revision, and final polishing of 
manuscript. All authors contributed to the article and approved the submitted version.

\section{FUNDING}

This study was supported by the National Science Foundation of China (Nos. 41776134, 91851210, 41673073, 41530105, and 41776137 ), the State Key R\&D project of China grant (No. 2018YFA0605800), the Laboratory for Marine Geology, Qingdao National Laboratory for Marine Science and Technology (No. MGQNLM-TD 201810), the Shenzhen Key Laboratory of Marine Archaea Geo-Omics, Southern University of Science and Technology (No. ZDSYS 20180208184349083), and the Southern Marine Science and Engineering Guangdong Laboratory (Guangzhou) (No. K19313901) Project of China Geological Survey (DD20191002). Travel of DXL to the International Workshop on Geo-omics of Archaea to present

\section{REFERENCES}

Abby, S. S., Melcher, M., Kerou, M., Krupovic, M., Stieglmeier, M., Rossel, C., et al. (2018). Candidatus Nitrosocaldus cavascurensis, an ammonia oxidizing, extremely thermophilic archaeon with a highly mobile genome. Front. Microbiol. 9:28. doi: 10.3389/fmicb.2018.00028

Aller, R. C., and Blair, N. E. (2004). Early diagenetic remineralization of sedimentary organic $\mathrm{C}$ in the Gulf of Papua deltaic complex (Papua New Guinea): net loss of terrestrial $\mathrm{C}$ and diagenetic fractionation of C isotopes. Geochim. Cosmochim. Acta 68, 1815-1825. doi: $10.1016 /$ j.gca.2003.10.028

Alves, R. J. E., Minh, B. Q., Urich, T., von Haeseler, A., and Schleper, C. (2018). Unifying the global phylogeny and environmental distribution of ammoniaoxidising archaea based on amoA genes. Nat. Commun. 9:1517. doi: 10.1038/ s41467-018-03861-1

Bates, S. T., Berg-Lyons, D., Caporaso, J. G., Walters, W. A., Knight, R., and Fierer, N. (2011). Examining the global distribution of dominant archaeal populations in soil. ISME J. 5, 908-917. doi: 10.1038/ismej.2010.171

Bi, X., Sheng, G., Liu, X., Li, C., and Fu, J. (2005). Molecular and carbon and hydrogen isotopic composition of n-alkanes in plant leaf waxes. Org. Geochem. 36, 1405-1417. doi: 10.1016/j.orggeochem.2005.06.001

Biddle, J. F., Lipp, J. S., Lever, M. A., Lloyd, K. G., Sørensen, K. B., Anderson, R., et al. (2006). Heterotrophic archaea dominate sedimentary subsurface ecosystems off Peru. Proc. Natl. Acad. Sci. U.S.A. 103, 3846-3851. doi: 10.1073/ pnas.0600035103

Blattmann, T. M., Liu, Z., Zhang, Y., Zhao, Y., Haghipour, N., Montluçon, D. B., et al. (2019). Mineralogical control on the fate of continentally derived organic matter in the ocean. Science 366, 742-745. doi: 10.1126/science.aax5345

Bouskill, N. J., Eveillard, D., Chien, D., Jayakumar, A., and Ward, B. B. (2012). Environmental factors determining ammonia-oxidizing organism distribution and diversity in marine environments. Environ. Microbiol. 14, 714-729. doi: 10.1111/j.1462-2920.2011.02623.x

Cartapanis, O., Bianchi, D., Jaccard, S. L., and Galbraith, E. D. (2016). Global pulses of organic carbon burial in deep-sea sediments during glacial maxima. Nat. Commun. 7:10796. doi: 10.1038/ncomms10796

Casamayor, E. O., Massana, R., Benlloch, S., Ovreas, L., Diez, B., Goddard, V. J., et al. (2002). Changes in archaeal, bacterial and eukaryal assemblages along a salinity gradient by comparison of genetic fingerprinting methods in a Multipond solar Saltern. Environ. Microbiol. 4, 338-348. doi: 10.1046/j.14622920.2002.00297.x

Cerqueira, T., Pinho, D., Froufe, H., Santos, R. S., Bettencourt, R., and Egas, C. (2017). Sediment microbial diversity of three deep-sea hydrothermal vents southwest of the Azores. Microb. Ecol. 74, 332-349. doi: 10.1007/s00248-0170943-9 this work was funded by the United States National Science Foundation (DEB 1928924).

\section{ACKNOWLEDGMENTS}

We thank Songze Chen and Haodong Liu for the laboratory assistance work and Ying Sun for the help of phylogenetic analysis. We also thank Jinju Kan for important suggestions on manuscript writing. We appreciate the help of the crew onboard the R/V Marion Dufrene during MD190-CIRCEA cruise.

\section{SUPPLEMENTARY MATERIAL}

The Supplementary Material for this article can be found online at: https://www.frontiersin.org/articles/10.3389/fmicb. 2020.572017/full\#supplementary-material

Cole, J. K., Peacock, J. P., Dodsworth, J. A., Williams, A. J., Thompson, D. B., Dong, H., et al. (2013). Sediment microbial communities in great boiling spring are controlled by temperature and distinct from water communities. ISME J. 7, 718-729. doi: 10.1038/ismej.2012.157

Cui, H., Su, X., Chen, F., Wei, S., Chen, S., and Wang, J. (2016). Vertical distribution of archaeal communities in cold seep sediments from the Jiulong methane reef area in the south China sea. Biosci. J. 32, 1059-1068. doi: 10.14393/bjv32n4a2016-33994

Curry, K. J., Bennett, R. H., Mayer, L. M., Curry, A., Abril, M., Biesiot, P. M., et al. (2007). Direct visualization of clay microfabric signatures driving organic matter preservation in fine-grained sediment. Geochim. Cosmochim. Acta 71, 1709-1720. doi: 10.1016/j.gca.2007.01.009

Dai, T., Zhang, Y., Tang, Y., Bai, Y., Tao, Y., Huang, B., et al. (2016). Identifying the key taxonomic categories that characterize microbial community diversity using full-scale classification: a case study of microbial communities in the sediments of Hangzhou Bay. FEMS Microbiol. Ecol. 92:fiw150. doi: 10.1093/ femsec/fiw 150

Dang, H., Luan, X.-W., Chen, R., Zhang, X., Guo, L., and Klotz, M. G. (2010). Diversity, abundance and distribution of amoA-encoding archaea in deep-sea methane seep sediments of the Okhotsk Sea. FEMS Microbiol. Ecol. 72, 370-385. doi: 10.1111/j.1574-6941.2010.00870.x

Danovaro, R., Corinaldesi, C., Rastelli, E., and Anno, A. D. (2015). Towards a better quantitative assessment of the relevance of deep-sea viruses, Bacteria and Archaea in the functioning of the ocean seafloor. Aquat. Microb. Ecol. 75, 81-90. doi: 10.3354/ame01747

Danovaro, R., Molari, M., Corinaldesi, C., and Dell'Anno, A. (2016). Macroecological drivers of archaea and bacteria in benthic deep-sea ecosystems. Sci. Adv. 2:e1500961. doi: 10.1126/sciadv.1500961

DeLong, E. F. (1992). Archaea in coastal marine environments. Proc. Natl. Acad. Sci. U.S.A. 89, 5685-5689.

D’Hondt, S., Inagaki, F., Zarikian, C. A., Abrams, L. J., Dubois, N., Engelhardt, T., et al. (2015). Presence of oxygen and aerobic communities from sea floor to basement in deep-sea sediments. Nat. Geosci. 8, 299-304. doi: 10.1038/ ngeo 2387

D’Hondt, S., Jørgensen, B. B., Miller, D. J., Batzke, A., Blake, R., Cragg, B. A., et al. (2004). Distributions of microbial activities in deep subseafloor sediments. Science 306, 2216-2221. doi: 10.1126/science.1101155

D'Hondt, S., Rutherford, S., and Spivack, A. J. (2002). Metabolic activity of subsurface life in deep-sea sediments. Science 295, 2067-2070. doi: 10.1126/ science. 1064878

Di, H. J., Cameron, K. C., Shen, J.-P., Winefield, C. S., O’Callaghan, M., Bowatte, S., et al. (2010). Ammonia-oxidizing bacteria and archaea grow under contrasting soil nitrogen conditions. FEMS Microbiol. Ecol. 72, 386-394. doi: 10.1111/j. 1574-6941.2010.00861.x 
Dorsaz, S., Charretier, Y., Girard, M., Gaïa, N., Leo, S., Schrenzel, J., et al. (2020). Changes in microbiota profiles after prolonged frozen storage of stool suspensions. Front. Cell. Infect. Microbiol. 10:77. doi: 10.3389/fcimb.2020.00077

Dunne, J. P., Sarmiento, J. L., and Gnanadesikan, A. (2007). A synthesis of global particle export from the surface ocean and cycling through the ocean interior and on the seafloor. Glob. Biogeochem. Cycles 21:GB4006. doi: 10.1029/ 2006GB002907

Durbin, A. M., and Teske, A. (2010). Sediment-associated microdiversity within the marine group I crenarchaeota. Environ. Microbiol. Rep. 2, 693-703. doi: 10.1111/j.1758-2229.2010.00163.x

Durbin, A. M., and Teske, A. (2012). Archaea in organic-lean and organic-rich marine subsurface sediments: an environmental gradient reflected in distinct phylogenetic lineages. Front. Microbiol. 3:168. doi: 10.3389/fmicb.2012.00168

Edgar, R. C., Haas, B. J., Clemente, J. C., Quince, C., and Knight, R. (2011). UCHIME improves sensitivity and speed of chimera detection. Bioinformatics 27, 2194-2200. doi: 10.1093/bioinformatics/btr381

Elovitz, M. A., Gajer, P., Riis, V., Brown, A. G., Humphrys, M. S., Holm, J. B., et al. (2019). Cervicovaginal microbiota and local immune response modulate the risk of spontaneous preterm delivery. Nat. Commun. 10:1305.

Fan, L., Wang, Z., Chen, M., Qu, Y., Li, J., Zhou, A., et al. (2019). Microbiota comparison of Pacific white shrimp intestine and sediment at freshwater and marine cultured environment. Sci. Total Environ. 657, 1194-1204. doi: 10.1016/ j.scitotenv.2018.12.069

Fillol, M., Sànchez-Melsió, A., Gich, F., and Borrego, C. M. (2015). Diversity of miscellaneous crenarchaeotic group archaea in freshwater karstic lakes and their segregation between planktonic and sediment habitats. FEMS Microbiol. Ecol. 91:fiv020.

Francis, C. A., Roberts, K. J., Beman, J. M., Santoro, A. E., and Oakley, B. B. (2005). Ubiquity and diversity of ammonia-oxidizing archaea in water columns and sediments of the ocean. Proc. Natl. Acad. Sci. U.S.A. 102, 14683-14688. doi: 10.1073/pnas.0506625102

Hallam, S. J., Mincer, T. J., Schleper, C., Preston, C. M., Roberts, K., Richardson, P. M., et al. (2006). Pathways of carbon assimilation and ammonia oxidation suggested by environmental genomic analyses of marine Crenarchaeota. PLoS Biol. 4:e95. doi: 10.1371/journal.pbio.0040095

Hamdan, L. J., Coffin, R. B., Sikaroodi, M., Greinert, J., Treude, T., and Gillevet, P. M. (2013). Ocean currents shape the microbiome of Arctic marine sediments. ISME J. 7, 685-696. doi: 10.1038/ismej.2012.143

He, D., Ladd, S. N., Saunders, C. J., Mead, R. N., and Jaffé, R. (2020). Distribution of $\mathrm{n}$-alkanes and their $\mathrm{d} 2 \mathrm{H}$ and $\mathrm{d} 13 \mathrm{C}$ values in typical plants along a terrestrialcoastal-oceanic gradient. Geochim. Cosmochim. Acta 281, 31-52. doi: 10.1016/ j.gca.2020.05.003

He, Y., Li, M., Perumal, V., Feng, X., Fang, J., Xie, J., et al. (2016). Genomic and enzymatic evidence for acetogenesis among multiple lineages of the archaeal phylum Bathyarchaeota widespread in marine sediments. Nat. Microbiol. $1: 16035$.

Hedges, J. I., Keil, R. G., and Benner, R. (1997). What happens to terrestrial organic matter in the ocean? Org. Geochem. 27, 195-212. doi: 10.1016/s0146-6380(97) 00066- 1

Hedlund, B. P., Thomas, S. C., Dodsworth, J. A., and Zhang, C. L. (2016). "Life in high-temperature environments," in Manual of Environmental Microbiology, 4th Edn, eds M. V. Yates, C. H. Nakatsu, R. V. Miller, and S. D. Pillai, (Washington, DC: ASM Press), 863-887.

Heijs, S. K., Laverman, A. M., Forney, L. J., Hardoim, P. R., and Van Elsas, J. D. (2008). Comparison of deep-sea sediment microbial communities in the Eastern Mediterranean. FEMS Microbiol. Ecol. 64, 362-377. doi: 10.1111/j. 1574-6941.2008.00463.x

Higginson, M. J., Maxwell, J. R., and Altabet, M. A. (2003). Nitrogen isotope and chlorin paleoproductivity records from the Northern South China Sea: remote vs. local forcing of millennial-and orbital-scale variability. Mar. Geol. 201, 223-250. doi: 10.1016/S0025-3227(03)00218-4

Hiraoka, S., Hirai, M., Matsui, Y., Makabe, A., Minegishi, H., Tsuda, M., et al. (2020). Microbial community and geochemical analyses of trans-trench sediments for understanding the roles of hadal environments. ISME J. 14, 740-756. doi: 10.1038/s41396-019-0564-z

Hong, J. K., and Cho, J. C. (2015). Environmental variables shaping the ecological niche of thaumarchaeota in soil: direct and indirect causal effects. PLoS One 10:e0133763. doi: 10.1371/journal.pone. 0133763
Hoshino, T., and Inagaki, F. (2019). Abundance and distribution of Archaea in the subseafloor sedimentary biosphere. ISME J. 13, 227-231. doi: 10.1038/s41396018-0253-3

Howe, K., Bateman, A., and Durbin, R. (2002). QuickTree: building huge Neighbour-Joining trees of protein sequences. Bioinformatics 18, 1546-1547. doi: 10.1093/bioinformatics/18.11.1546

Imachi, H., Nobu, M. K., Nakahara, N., Morono, Y., Ogawara, M., Takaki, Y., et al. (2020). Isolation of an archaeon at the prokaryote-eukaryote interface. Nature $577,519-525$.

Inagaki, F., Hinrichs, K.-U., Kubo, Y., Bowles, M. W., Heuer, V. B., Hong, W.L., et al. (2015). Exploring deep microbial life in coal-bearing sediment down to $2.5 \mathrm{~km}$ below the ocean floor. Science 349, 420-424. doi: 10.1126/science. aaa6882

Inagaki, F., Nunoura, T., Nakagawa, S., Teske, A., Lever, M., Lauer, A., et al. (2006). Biogeographical distribution and diversity of microbes in methane hydratebearing deep marine sediments on the Pacific Ocean Margin. Proc. Natl. Acad. Sci. U.S.A. 103, 2815-2820. doi: 10.1073/pnas.0511033103

Jia, Z., and Conrad, R. (2009). Bacteria rather than Archaea dominate microbial ammonia oxidation in an agricultural soil. Environ. Microbiol. 11, 1658-1671.

Jiang, H., Dong, H., Yu, B., Ye, Q., Shen, J., Rowe, H., et al. (2008). Dominance of putative marine benthic Archaea in Qinghai Lake, north-western China. Environ. Microbiol. 10, 2355-2367. doi: 10.1111/j.1462-2920.2008.01661.x

Jorgensen, S. L., Hannisdal, B., Lanzén, A., Baumberger, T., Flesland, K., Fonseca, R., et al. (2012). Correlating microbial community profiles with geochemical data in highly stratified sediments from the Arctic Mid-Ocean Ridge. Proc. Natl. Acad. Sci. U.S.A. 109, E2846-E2855. doi: 10.1073/pnas.1207574109

Könneke, M., Bernhard, A. E., José, R., Walker, C. B., Waterbury, J. B., and Stahl, D. A. (2005). Isolation of an autotrophic ammonia-oxidizing marine archaeon. Nature 437, 543-546. doi: 10.1038/nature03911

Kubo, K., Lloyd, K. G., Biddle, J. F., Amann, R., Teske, A., and Knittel, K. (2012). Archaea of the Miscellaneous Crenarchaeotal Group are abundant, diverse and widespread in marine sediments. ISME J. 6, 1949-1965. doi: 10.1038/ismej. 2012.37

Lauer, A., Sørensen, K. B., and Teske, A. (2016). Phylogenetic characterization of marine benthic archaea in organic-poor sediments of the eastern equatorial pacific ocean (ODP site 1225). Microorganisms 4:32. doi: 10.3390/ microorganisms 4030032

Learman, D. R., Henson, M. W., Thrash, J. C., Temperton, B., Brannock, P. M., Santos, S. R., et al. (2016). Biogeochemical and microbial variation across 5500 $\mathrm{km}$ of Antarctic surface sediment implicates organic matter as a driver of benthic community structure. Front. Microbiol. 7:284. doi: 10.3389/fmicb.2016. 00284

Lehtovirta-Morley, L. E., Ross, J., Hink, L., Weber, E. B., Gubry-Rangin, C., Thion, C., et al. (2016). Isolation of 'Candidatus Nitrosocosmicus franklandus', a novel ureolytic soil archaeal ammonia oxidiser with tolerance to high ammonia concentration. FEMS Microbiol. Ecol. 92:fiw057. doi: 10.1093/femsec/fiw057

Levičnik-Höfferle, Š., Nicol, G. W., Ausec, L., Mandić-Mulec, I., and Prosser, J. I. (2012). Stimulation of thaumarchaeal ammonia oxidation by ammonia derived from organic nitrogen but not added inorganic nitrogen. FEMS Microbiol. Ecol. 80, 114-123. doi: 10.1111/j.1574-6941.2011.01275.x

Li, M., Baker, B. J., Anantharaman, K., Jain, S., Breier, J. A., and Dick, G. J. (2015). Genomic and transcriptomic evidence for scavenging of diverse organic compounds by widespread deep-sea archaea. Nat. Commun. 6:8933. doi: 10. 1038/ncomms9933

Li, Y., Li, F., Zhang, X., Qin, S., Zeng, Z., Dang, H., et al. (2008). Vertical distribution of bacterial and archaeal communities along discrete layers of a deep-sea cold sediment sample at the East Pacific Rise $\left(\sim 13^{\circ} \mathrm{N}\right)$. Extremophiles 12, 573-585. doi: 10.1007/s00792-008-0159-5

Lin, B.-S., Lee, C.-L., Brimblecombe, P., and Liu, J. T. (2016). Transport and fluxes of terrestrial polycyclic aromatic hydrocarbons in a small mountain river and submarine canyon system. J. Environ. Manage. 178, 30-41. doi: 10.1016/j. jenvman.2016.04.039

Lipp, J. S., Morono, Y., Inagaki, F., and Hinrichs, K.-U. (2008). Significant contribution of Archaea to extant biomass in marine subsurface sediments. Nature 454, 991-994. doi: 10.1038/nature07174

Liu, C., Li, H., Zhang, Y., Si, D., and Chen, Q. (2016). Evolution of microbial community along with increasing solid concentration during high-solids 
anaerobic digestion of sewage sludge. Bioresour. Technol. 216, 87-94. doi: 10.1016/j.biortech.2016.05.048

Liu, C., Li, X., Chen, Y., Cheng, Z., Duan, Q., Meng, Q., et al. (2017). Age-related response of rumen microbiota to mineral salt and effects of their interactions on enteric methane emissions in cattle. Microb. Ecol. 73, 590-601. doi: 10.1007/ s00248-016-0888-4

Liu, H., Zhang, C. L., Yang, C., Chen, S., Cao, Z., Zhang, Z., et al. (2017). Marine Group II dominates planktonic Archaea in water column of the Northeastern South China Sea. Front. Microbiol. 8:1098. doi: 10.3389/fmicb.2017. 01098

Liu, J., Yu, S., Zhao, M., He, B., and Zhang, X. H. (2014). Shifts in archaeaplankton community structure along ecological gradients of Pearl Estuary. FEMS Microbiol. Ecol. 90, 424-435. doi: 10.1111/1574-6941.12404

Lloyd, K. G., Schreiber, L., Petersen, D. G., Kjeldsen, K. U., Lever, M. A., Steen, A. D., et al. (2013). Predominant archaea in marine sediments degrade detrital proteins. Nature 496, 215-218. doi: 10.1038/nature12033

Lou, J., Yang, L., Wang, H., Wu, L., and Xu, J. (2018). Assessing soil bacterial community and dynamics by integrated high-throughput absolute abundance quantification. PeerJ 6:e4514. doi: 10.7717/peerj. 4514

Lu, X., Heal, K. R., Ingalls, A. E., Doxey, A. C., and Neufeld, J. D. (2020). Metagenomic and chemical characterization of soil cobalamin production. ISME J. 14, 53-66. doi: 10.1038/s41396-019-0502-0

Mackenzie, F. T., Lerman, A., and Andersson, A. J. (2004). Past and present of sediment and carbon biogeochemical cycling models. Biogeosciences 1, 11-32. doi: 10.5194/bg-1-11-2004

Molnar, P. (2004). Late Cenozoic increase in accumulation rates of terrestrial sediment: how might climate change have affected erosion rates? Annu. Rev. Earth Planet. Sci. 32, 67-89. doi: 10.1146/annurev.earth.32.091003.143456

Müller, P. J., and Suess, E. (1979). Productivity, sedimentation rate, and sedimentary organic matter in the oceans-I. Organic carbon preservation. Deep Sea Res. Part I Oceanogr. Res. Pap. 26, 1347-1362. doi: 10.1016/01980149(79)90003-7

Mußmann, M., Brito, I., Pitcher, A., Damsté, J. S. S., Hatzenpichler, R., Richter, A., et al. (2011). Thaumarchaeotes abundant in refinery nitrifying sludges express amoA but are not obligate autotrophic ammonia oxidizers. Proc. Natl. Acad. Sci. U.S.A. 108, 16771-16776. doi: 10.1073/pnas.1106427108

Nunoura, T., Inagaki, F., Delwiche, M. E., Colwell, F. S., and Takai, K. (2008). Subseafloor microbial communities in methane hydrate-bearing sediment at two distinct locations (ODP Leg204) in the Cascadia margin. Microbes Environ. 23, 317-325. doi: 10.1264/jsme2.me08514

Nunoura, T., Nishizawa, M., Kikuchi, T., Tsubouchi, T., Hirai, M., Koide, O., et al. (2013). Molecular biological and isotopic biogeochemical prognoses of the nitrification-driven dynamic microbial nitrogen cycle in hadopelagic sediments. Environ. Microbiol. 15, 3087-3107. doi: 10.1111/1462-2920.12152

Nunoura, T., Soffientino, B., Blazejak, A., Kakuta, J., Oida, H., Schippers, A., et al. (2009). Subseafloor microbial communities associated with rapid turbidite deposition in the Gulf of Mexico continental slope (IODP Expedition 308). FEMS Microbiol. Ecol. 69, 410-424. doi: 10.1111/j.1574-6941.2009.00718.x

Offre, P., Spang, A., and Schleper, C. (2013). Archaea in biogeochemical cycles. Annu. Rev. Microbiol. 67, 437-457. doi: 10.1146/annurev-micro-092412155614

Ohene-Adjei, S., Teather, R. M., Ivanj, M., and Forster, R. J. (2007). Postinoculation protozoan establishment and association patterns of methanogenic archaea in the ovine rumen. Appl. Environ. Microbiol. 73, 4609-4618. doi: 10.1128/Aem. 02687-06

Orsi, W. D. (2018). Ecology and evolution of seafloor and subseafloor microbial communities. Nat. Rev. Microbiol. 16, 671-683. doi: 10.1038/s41579-0180046-8

Orsi, W. D., Vuillemin, A., Rodriguez, P., Coskun, Ö. K., Gomez-Saez, G. V., Lavik, G., et al. (2020). Metabolic activity analyses demonstrate that Lokiarchaeon exhibits homoacetogenesis in sulfidic marine sediments. Nat. Microbiol. 5, 248-255. doi: 10.1038/s41564-019-0630-3

Pan, J., Zhou, Z., Béjà, O., Cai, M., Yang, Y., Liu, Y., et al. (2020). Genomic and transcriptomic evidence of light-sensing, porphyrin biosynthesis, CalvinBenson-Bassham cycle, and urea production in Bathyarchaeota. Microbiome 8, 1-12.
Park, S.-J., Park, B.-J., and Rhee, S.-K. (2008). Comparative analysis of archaeal 16S rRNA and amoA genes to estimate the abundance and diversity of ammoniaoxidizing archaea in marine sediments. Extremophiles 12, 605-615. doi: 10. 1007/s00792-008-0165-7

Parkes, R. J., Cragg, B., Roussel, E., Webster, G., Weightman, A., and Sass, H. (2014). A review of prokaryotic populations and processes in sub-seafloor sediments, including biosphere: geosphere interactions. Mar. Geol. 352, 409425. doi: 10.1016/j.margeo.2014.02.009

Pelikan, C., Jaussi, M., Wasmund, K., Seidenkrantz, M.-S., Pearce, C., Kuzyk, Z. Z. A., et al. (2019). Glacial runoff promotes deep burial of sulfur cyclingassociated microorganisms in marine sediments. Front. Microbiol. 10:2558. doi: 10.3389/fmicb.2019.02558

Prahl, F. G., De Lange, G. J., Scholten, S., and Cowie, G. L. (1997). A case of post-depositional aerobic degradation of terrestrial organic matter in turbidite deposits from the Madeira Abyssal Plain. Org. Geochem. 27, 141-152. doi: 10.1016/s0146-6380(97)00078-8

Prokopenko, M. G., Hammond, D. E., Spivack, A., and Stott, L. (2006). "Impact of longterm diagenesis on $\delta^{15} \mathrm{~N}$ of organic matter in marine sediments: sites 1227 and 1230," in Proceedings of the Ocean Drilling Program: Scientific Results 201, 1-30. doi: 10.2973/odp.proc.sr.201.117.2006

Qin, W., Amin, S. A., Martens-Habbena, W., Walker, C. B., Urakawa, H., Devol, A. H., et al. (2014). Marine ammonia-oxidizing archaeal isolates display obligate mixotrophy and wide ecotypic variation. Proc. Natl. Acad. Sci. U.S.A. 111, 12504-12509. doi: 10.1073/pnas.1324115111

Qin, W., Zheng, Y., Zhao, F., Wang, Y., Urakawa, H., Martens-Habbena, W., et al. (2020). Alternative strategies of nutrient acquisition and energy conservation map to the biogeography of marine ammonia-oxidizing archaea. ISME J. 14, 2595-2609. doi: 10.1038/s41396-020-0710-7

Rinke, C., Rubino, F., Messer, L. F., Youssef, N., Parks, D. H., Chuvochina, M., et al. (2019). A phylogenomic and ecological analysis of the globally abundant Marine Group II archaea (Ca. Poseidoniales ord. nov.). ISME J. 13, 663-675. doi: 10.1038/s41396-018-0282-y

Schloss, P. D., Westcott, S. L., Ryabin, T., Hall, J. R., Hartmann, M., Hollister, E. B., et al. (2009). Introducing mothur: open-source, platform-independent, community-supported software for describing and comparing microbial communities. Appl. Environ. Microbiol. 75, 7537-7541. doi: 10.1128/aem. 01541-09

Schneider, D., Engelhaupt, M., Allen, K., Kurniawan, S., Krashevska, V., Heinemann, M., et al. (2015). Impact of lowland rainforest transformation on diversity and composition of soil prokaryotic communities in Sumatra (Indonesia). Front. Microbiol. 6:1339. doi: 10.3389/fmicb.2015.01339

Schubert, C. J., and Calvert, S. E. (2001). Nitrogen and carbon isotopic composition of marine and terrestrial organic matter in Arctic Ocean sediments: implications for nutrient utilization and organic matter composition. Deep Sea Res. Part I Oceanogr. Res. Pap. 48, 789-810. doi: 10.1016/s0967-0637(00)00 069-8

Seeberg-Elverfeldt, J., Schlüter, M., Feseker, T., and Kölling, M. (2005). Rhizon sampling of porewaters near the sediment-water interface of aquatic systems. Limnol. Oceanogr. Methods 3, 361-371. doi: 10.4319/lom.2005. 3.361

Seiter, K., Hensen, C., Schröter, J., and Zabel, M. (2004). Organic carbon content in surface sediments-defining regional provinces. Deep Sea Res. Part I Oceanogr. Res. Pap. 51, 2001-2026. doi: 10.1016/j.dsr.2004.06.014

Seki, O., Kawamura, K., Nakatsuka, T., Ohnishi, K., Ikehara, M., Wakatsuchi, M. (2003). Sediment core profiles of long-chain n-alkanes in the Sea of Okhotsk: enhanced transport of terrestrial organic matter from the last deglaciation to the early Holocene. Geophys. Res. Lett. 30, 1-1. doi: 10.1029/2001GL014464

Shannon, P., Markiel, A., Ozier, O., Baliga, N. S., Wang, J. T., Ramage, D., et al. (2003). Cytoscape: a software environment for integrated models of biomolecular interaction networks. Genome Res. 13, 2498-2504. doi: 10.1101/ gr.1239303

Smith, C. R., De Leo, F. C., Bernardino, A. F., Sweetman, A. K., and Arbizu, P. M. (2008). Abyssal food limitation, ecosystem structure and climate change. Trends Ecol. Evol. 23, 518-528. doi: 10.1016/j.tree.2008.05.002

Sørensen, K. B., and Teske, A. (2006). Stratified communities of active archaea in deep marine subsurface sediments. Appl. Environ. Microbiol. 72, 4596-4603. doi: 10.1128/aem.00562-06 
Stein, R. (1990). Organic carbon content/sedimentation rate relationship and its paleoenvironmental significance for marine sediments. Geo Mar. Lett. 10, 37-44. doi: 10.1007/bf02431020

Stieglmeier, M., Klingl, A., Alves, R. J. E., Rittmann, S., Melcher, M., Leisch, N., et al. (2014). Nitrososphaera viennensis gen. nov., sp nov., an aerobic and mesophilic, ammonia-oxidizing archaeon from soil and a member of the archaeal phylum Thaumarchaeota. Int. J. Syst. Evol. Microbiol. 64, 2738-2752. doi: 10.1099/ijs.0. 063172-0

Storey, J. D. (2003). The positive false discovery rate: a Bayesian interpretation and the q-value. Ann. Stat. 31, 2013-2035. doi: 10.1214/aos/1074290335

Takano, Y., Chikaraishi, Y., Ogawa, N. O., Nomaki, H., Morono, Y., Inagaki, F., et al. (2010). Sedimentary membrane lipids recycled by deep-sea benthic archaea. Nat. Geosci. 3, 858-861. doi: 10.1038/ngeo983

Tang, C., Zhou, D., Endler, R., Lin, J., and Harff, J. (2010). Sedimentary development of the Pearl River Estuary based on seismic stratigraphy. J. Mar. Syst. 82, S3-S16. doi: 10.1016/j.jmarsys.2010.02.001

Tourna, M., Stieglmeier, M., Spang, A., Könneke, M., Schintlmeister, A., Urich, T., et al. (2011). Nitrososphaera viennensis, an ammonia oxidizing archaeon from soil. Proc. Natl. Acad. Sci. U.S.A. 108, 8420-8425. doi: 10.1073/pnas.1013488108

Vigneron, A., Cruaud, P., Roussel, E. G., Pignet, P., Caprais, J.-C., Callac, N., et al. (2014). Phylogenetic and functional diversity of microbial communities associated with subsurface sediments of the Sonora Margin, Guaymas Basin. PLoS One 9:e104427. doi: 10.1371/journal.pone.0104427

Vuillemin, A., Wankel, S. D., Coskun, Ö. K., Magritsch, T., Vargas, S., Estes, E. R., et al. (2019). Archaea dominate oxic subseafloor communities over multimillion-year time scales. Sci. Adv. 5:eaaw4108. doi: 10.1126/sciadv. aaw 4108

Wang, P., Li, T., Hu, A., Wei, Y., Guo, W., Jiao, N., et al. (2010). Community structure of archaea from deep-sea sediments of the South China Sea. Microb. Ecol. 60, 796-806. doi: 10.1007/s00248-010-9746-y

Wang, P., Wei, Y., Li, T., Li, F., Meng, J., and Zhang, C. L. (2014). Archaeal diversity and spatial distribution in the surface sediment of the South China Sea. Geomicrobiol. J. 31, 1-11. doi: 10.1080/01490451.2013.797522

Wang, P., Zhang, T., Chen, S., Li, X., Lai, D., Gao, S., et al. (2020a). Niche specificity and potential terrestrial organic carbon utilization of benthic Bathyarchaeota in a eutrophic subtropic estuarine system. Chem. Geol. 556:119839. doi: 10.1016/j. chemgeo.2020.119839

Wang, W., Tao, J., Liu, H., Li, P., Chen, S., Wang, P., et al. (2020b). Contrasting bacterial and archaeal distributions reflecting different geochemical processes in a sediment core from the Pearl River Estuary. AMB Express 10:16. doi: 10.1186/s13568-020-0950-y

Wen, X., Yang, S., Horn, F., Winkel, M., Wagner, D., and Liebner, S. (2017). Global biogeographic analysis of methanogenic archaea identifies community-shaping environmental factors of natural environments. Front. Microbiol. 8:1339. doi: 10.3389/fmicb.2017.01339

Whitman, W. B., Coleman, D. C., and Wiebe, W. J. (1998). Prokaryotes: the unseen majority. Proc. Natl. Acad. Sci. U.S.A. 95, 6578-6583. doi: 10.1073/pnas.95.12. 6578

Wickham, H. (2011). ggplot2. Wiley Interdiscip. Rev. Comput. Stat. 3, 180-185. doi: $10.1002 /$ wics. 147

Willenbring, J. K., and von Blanckenburg, F. (2010). Long-term stability of global erosion rates and weathering during late-Cenozoic cooling. Nature 465, $211-$ 214. doi: 10.1038/nature09044

Wu, C., Ren, J., Bao, Y., Lei, Y., and Shi, H. (2007). A long-term morphological modeling study on the evolution of the Pearl River Delta, network system, and estuarine bays since 6000 yr BP. Geol. Soc. Am. Spec. Pap. 426, 199-214. doi: $10.1130 / 2007.2426$

Xia, L. C., Ai, D., Cram, J., Fuhrman, J. A., and Sun, F. (2013). Efficient statistical significance approximation for local similarity analysis of high-throughput time series data. Bioinformatics 29, 230-237. doi: 10.1093/bioinformatics/bts668

Xia, L. C., Steele, J. A., Cram, J. A., Cardon, Z. G., Simmons, S. L., Vallino, J. J., et al. (2011). Extended local similarity analysis (eLSA) of microbial community and other time series data with replicates. BMC Syst. Biol. 5(Suppl. 2):S15. doi: 10.1186/1752-0509-5-S2-S15

Yamamoto, M., and Polyak, L. (2009). Changes in terrestrial organic matter input to the Mendeleev Ridge, western Arctic Ocean, during the Late Quaternary. Glob. Planet. Change 68, 30-37. doi: 10.1016/j.gloplacha.2009.03.012

Yu, T., Wu, W., Liang, W., Lever, M. A., Hinrichs, K.-U., and Wang, F. (2018). Growth of sedimentary Bathyarchaeota on lignin as an energy source. Proc. Natl. Acad. Sci. U.S.A. 115, 6022-6027. doi: 10.1073/pnas.1718854115

Zhang, C., Dang, H., Azam, F., Benner, R., Legendre, L., Passow, U., et al. (2018). Evolving paradigms in biological carbon cycling in the ocean. Natl. Sci. Rev. 5, 481-499. doi: 10.1093/nsr/nwy074

Zhang, C. L., Xie, W., Martin-Cuadrado, A.-B., and Rodriguez-Valera, F. (2015). Marine group II archaea, potentially important players in the global ocean carbon cycle. Front. Microbiol. 6:1108. doi: 10.3389/fmicb.2015.01108

Zhang, C. L., Ye, Q., Huang, Z., Li, W., Chen, J., Song, Z., et al. (2008). Global occurrence of archaeal amoA genes in terrestrial hot springs. Appl. Environ. Microbiol. 74, 6417-6426. doi: 10.1128/aem.00843-08

Zhao, S., Liu, Z., Chen, Q., Wang, X., Shi, J., Jin, H., et al. (2017). Spatiotemporal variations of deep-sea sediment components and their fluxes since the last glaciation in the northern South China Sea. Sci. China Earth Sci. 60, 1368-1381. doi: 10.1007/s11430-016-9058-6

Zhou, B., Zheng, H., Yang, W., Taylor, D., Lu, Y., Wei, G., et al. (2012). Climate and vegetation variations since the LGM recorded by biomarkers from a sediment core in the northern South China Sea. J. Quat. Sci. 27, 948-955. doi: 10.1002/ jqs. 2588

Zhou, Z., Liu, Y., Lloyd, K. G., Pan, J., Yang, Y., Gu, J.-D., et al. (2019). Genomic and transcriptomic insights into the ecology and metabolism of benthic archaeal cosmopolitan, Thermoprofundales (MBG-D archaea). ISME J. 13, 885-901. doi: 10.1038/s41396-018-0321-8

Zhou, Z., Pan, J., Wang, F., Gu, J.-D., and Li, M. (2018). Bathyarchaeota: globally distributed metabolic generalists in anoxic environments. FEMS Microbiol. Rev. 42, 639-655. doi: 10.1093/femsre/fuy023

Zinke, L. A., Glombitza, C., Bird, J. T., Rey, H., Jorgensen, B. B., Lloyd, K. G., et al. (2019). Microbial organic matter degradation potential in Baltic Sea sediments is influenced by depositional conditions and in situ geochemistry. Appl. Environ. Microbiol. 85:e02164-18. doi: 10.1128/AEM.02164-18

Conflict of Interest: The authors declare that the research was conducted in the absence of any commercial or financial relationships that could be construed as a potential conflict of interest.

Copyright (c) 2020 Lai, Hedlund, Xie, Liu, Phelps, Zhang and Wang. This is an open-access article distributed under the terms of the Creative Commons Attribution License (CC BY). The use, distribution or reproduction in other forums is permitted, provided the original author(s) and the copyright owner(s) are credited and that the original publication in this journal is cited, in accordance with accepted academic practice. No use, distribution or reproduction is permitted which does not comply with these terms. 